\title{
MÉTODOS DE DETERMINAÇÃO E VARIABILIDADE ESPACIAL DA CONDUTIVIDADE HIDRÁULICA SOB CONDIÇÕES DE CAMPO
}

\author{
LUIS CARLOS UCHÔA SAUNDERS
}

Orientador: Dr. KLAUS REICHARDT

Tese a presentada à Escola Superio" de Agricultura "Luiz de Queiroz", da Universidade de São Paulo, para obtenção do titulo de Doutor em Solos e Nutriçāo de Plantas.

$P \mid R A C I C A B A$

Estado de Săo Paulo - Brasil

1978 
. i.

À memória de meu querido pai,

Hugo Bezold Saunders

$\bar{A}$ minha mãe,

Arminda Uchôa Saunders

$E$ aos meus irmãos,

MINHA GRATIDAO

A minha esposa,

Sandra

$E$ aos meus filhos,

Agenor e Luis Carlos Ir.

DEDICO 
ii.

\section{AGRADECIMENTOS}

Ao concluir o presente trabalho o autor expressa seus agradecimen tos às pessoas e as instituições e em especial:

- Ao Prof. Klaus Reichardt, pela orientação precisa em todas as fases de preparação deste trabalho e pela amizade despretenciosa recebida durante a realização do curso.

- Ao colega Paulo Leonel Libardi, pela colaboração e sugestões prestadas no desenvolvimento de todo o trabalho.

- Aos colegas orientados do Prof. Klaus: Marcos, Fernando, Sidnei de, Ariovaldo, Lourival, Nelson e Cadima, pela amizade, incenti vo e colaboração.

- Ao Centro de Ciências Agrärias da Universidade Federal do Ceará e ao Departamento de Solos, Geologia e Fertilizantes da Escola Superior de Agricultura "Luiz de Queiroz" por possibilitarem a realização do presente trabalho.

- Ao Centro de Energia Nuclear na Agricultura (CENA) pelos recursos financeiros obtidos atravēs da Comissão de Energia Nuclear (CNEN) dentro do Projeto Feijão.

- A Agência Internacional de Energia Atômica (IAEA) pela participação no grupo de pesquisa coordenado sobre o uso de técnicas nucleares em estudos de regimes de ãgua.

- Ao Programa de Educação Agrícola Superior (PEAS) pela concessão da Bolsa de Pós-Graduação. 
.iii.

- Ao Conselho Nacional de Pesquisa (CNPq), pela concessão da bolsa de pesquisa.

- E a todos que direta ou indiretconente contribuirom para a reaZização deste trabalho. 


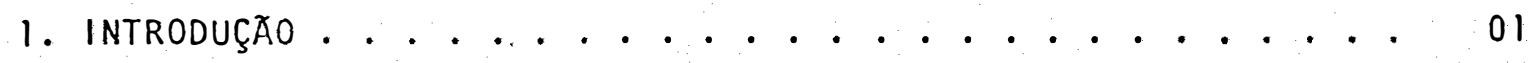

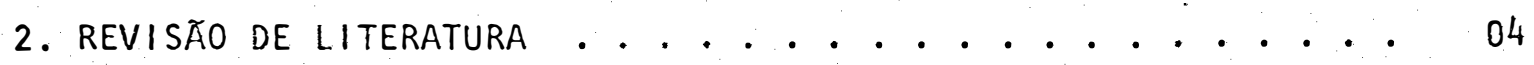

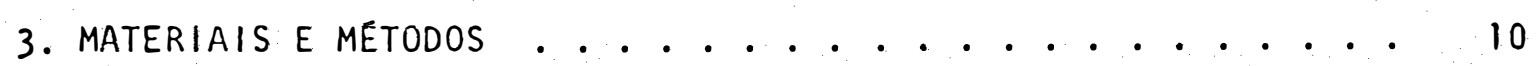

3.1. Descrição geral da ärea ................ 10

3.2. Medições a campo. . . . . . . . . . . . . 11

3.2.1. Parcela experimental ............. 11

3.2.2. Condutividade hidräulica saturada. ....... 11

3.2.3. Condutividade hidráulica não saturada. . . . . 12

3.2.3.1. Tensiômetros ........... 12

3.2.3.2. Tubos de acesso ......... 13

3.2.3.3. Sonda de neutrons ......... 13

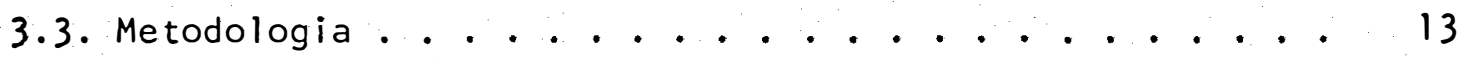

3.3.1. Condutividade hidräulica não saturada. . . . . 13

3.3.1.1. Base teörica . . . . . . . 13

3.3.1.2. Método de HILLEL et alii (1972). . . . 16

3.3.1.3. Método de HILLEL Modificado (1) . . . 17

3.3.1.4. Método de HILLEL Modificado (11).... 18

3.3 .1 .5 . Propagação de erros .......... 19 
Pägina

4. RESULTADOS E DISCUSSÃO . . . . . . . . . . . . . . 22

4.1. Condutividade hidráulica saturada . . . . . . . . 22

4.2. Condutividade hidráulica não saturada . . . . . . . . 22

4.2.1. Método de HILLEL et alii (1972)......... 25

4.2.2. Método de HILLEL Modificado (1) . . . . ... 43

4.2.3. Método de HILLEL Modificado (11) . . . . . . . 47

4.2.4. Propagação de erros .............. 53

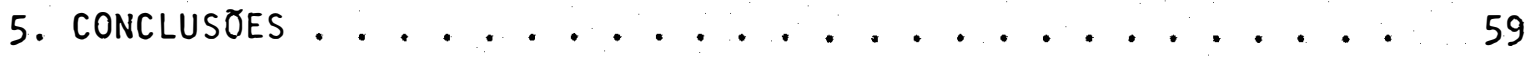

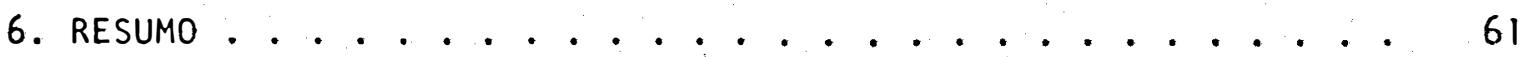

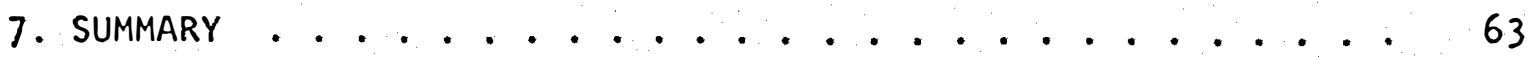

8. LITERATURA CITADA. . . . . . . . . . . . . . . 65 
.$v i$.

LISTA DAS FIGURAS

Figura

Página

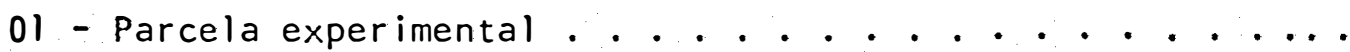

02 - Variação do conteúdo de água da camada $0-30 \mathrm{~cm}$ do solo durante o periodo de redistribuição, para os quatro locais escolhidos ao acaso na parcela experimental . . . . . .

03 - Variação do conteúdo de água da camada $30-60 \mathrm{~cm}$ do solo du rante o período de redistribuição para os quatro locais es colhidos ao acaso na parcela experimental ........

04 - Variação do conteúdo de água da camada $60-90 \mathrm{~cm}$ do solo durante o período de redistribuição para os quatro pontos escolhidos ao acaso na parcela experimental . . . . . .

05 - Variação do conteúdo de água da camada $90-120 \mathrm{~cm}$ do solo durante o periodo de redistribuição para os quatro locais escolhidos ao acaso na parcela experimental ......

06 - Variação média do conteúdo de água do solo durante o perío do de redistribuição nas camadas de $0-30,30-60,60-90$ e $90-120 \mathrm{~cm} \ldots \ldots \ldots \ldots . \ldots . \ldots . . \ldots$

07 - Variação média do potencial total da água do solo na parce la durante o período de redistribuição nas profundidades -

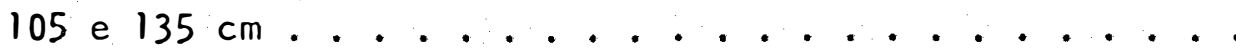

08 - Variação média do potencial total da água do solo no tubo de acesso $N_{1}$ durante 0 período de redistribuição nas profundidades de 105 e $135 \mathrm{~cm} \ldots \ldots . . . \ldots$ 
.vel.

Figura

Pägina

09 - Variação média do potencial total da água do solo no tubo de acesso $\mathrm{N}_{2}$ durante o período de redistribuição nas profundidades de 105 e $135 \mathrm{~cm}$. . . . . . . . ...

10 - Variação média do potencial total da água do solo do tubo de acesso $\mathrm{N}_{3}$ durante o período de redistribuição nas profundidades de 105 e $135 \mathrm{~cm}$. . . . . . . . . .

11 - Variação média do potencial total da água do solo no tubo de acesso $\mathrm{N}_{4}$ durante o período de redistribuição nas profundidades de 105 e $135 \mathrm{~cm}$. . . . . . . . . .

12 - Grä́fico da condutividade hidráulica (Método de HILLEL et alii, 1972) em função do conteúdo de água do solo para os quatro locais escolhidos ao acaso na parcela experimental com as respectivas equações de regressão e a curva mēdia..

13 - Variação do armazenamento da água do solo durante ó período de redistribuição na profundidade de $0-120 \mathrm{~cm}$. . .

14 - Gräfico da condutividade hidräulica |M̄étodo de HILLEL Modi ficado (1)] em função do conteūdo de àgua do solo para os quatro locais escolhidos ao acaso na parcela experimental com as respectivas equações de regressão e a curva média..

15 - Variação do armazenamento da água do solo durante o período de redistribuição para a profundidade de $0-120 \mathrm{~cm}$. .

16 - Grä́ico da condutividade hidräulica |M̄étodo de HILLEL Modificado (II)] em função do conteūdo de àgua do solo para os quatro locais escolhidos ao acaso na parcela experimen tal com as respectivas curvas de regressão e a curva média 
.viii.

17 - Valores médios da condutividade hidrăulica em função do conteüdo médio da água do solo para os 3 métodos estudados

18 - Normalização das curvas da condutividade hidrāulica em fun ção da umidade de saturação . . . . . . . . . . .

19 - Valores médios da condutividade hidráulica em função do con teúdo médio de água do solo. A área achureada representa o desvio padrão dos valores médios obtidos dos quatro locais escolhidos ao acaso na parcela experimental . . . . 58 
.$i x$.

\section{LISTA DAS TABELAS}

01 - Caracterização física do solo Terra Roxa Estruturada ...

02 - Conteúdo de água do solo $(\theta)$ durante o tempo de redistribuição no perfil, às profundidades de $30,60,90$ e $120 \mathrm{~cm}$.

03 - Potencial total da água do solo $(\Psi)$ durante o tempo de redistribuição no perfil, às profundidades de 105 e $135 \mathrm{~cm}$..

04 - Valores médios da densidade de fluxo (q) da água do solo às diversas profundidades $(Z)$ e diversos tempos $(t)$. (Meto do de HILLEL et alii, 1972). . . . . . . . . .

05 - Condutividade hidräulica em função do conteúdo de ăgua no solo médio (Método de HILLEL et alii, 1972)........

06 - Condutividade hidrāulica em função dos valores médios do armazenamento da água do solo na profundidade de $120 \mathrm{~cm}$ pa ra diversos tempos. Método de HILLEL Modificado (1) ...

07 - Condutividade hidráulica em função dos valores médios do armazenamento da água do solo na profundidade de $120 \mathrm{~cm}$ pa ra diversos tempos. A densidade de fluxo é calculada analiticamente pela expressão $q=\frac{b}{t}$. Método de HILLEL Modif cado (11).b $=0,7635 \ldots \ldots$

08 - Propagação de erros no cálculo da condutividade hidrăulica pelo método de HILLEL Modificado (1) . . . . . . . 


\section{INTRODUÇÃO}

A solução de problemas relacionados com irrigação, drenagem, recarga e poluição de àgua subterrânea, fluxo de ions no solo e conservação da água e do solo está intimamente ligada à quantificação do movimento da água do solo. Em condições de campo, geralmente o fluxo de àgua do solo é determinado indiretamente pela lei de DARCY, cuja maior di ficuldade de aplicação reside na determinação da condutividade hidräulica como uma função do conteúdo de água do solo. Devido a tạis fatos é que o estudo da quantificação do movimento da àgua do solo tem tomado um impulso muito grande nestas duas ültimas décadas, como pode ser observado pelo espaço considerâvel que ocupa este assunto na literatura.

A determinação da condutividade hidräulica tem sido realizada em grande escala em condições de laboratório; entretanto, tal procedimento pode conduzir a grandes erros ocasionados pela alteração das condições naturais do solo. Visando solucionar esta dificuldade, värios pes quisadores têm desenvolvido métodos de campo para sua obtenção e, também, para elucidar algumas dúvidas da possibilidade de utilização de dados obtidos sob condições de equilíbrio dinâmico em situações onde os proces- 
sos ocorrem sob condições transientes.

Um aspecto que tem sido investigado com grande ênfase, recentemente, é a variabilidade espacial inerente aos solos. Vários pesquisadores como NIELSEN et alii (1973), REICHARDT et alii (1976), FLÜHLER et alii (1976) e outros têm-se preocupado bastante com a variabilidade espacial da condutividade hidráulica em uma àrea de solo homogéneo do pon to de vista de classificação, e tambēm dentro de uma parcela experimental, pelo fato de terem observado que a média pode ficar mascarada quando o nümero de amostragem for relativamente pequeno, pois o evento mais provāvel é o valor da moda.

o presente trabalho foi desenvolvido em um Alfissol, situado no município de Piracicaba, onde o autor se propôs a realizar os se guintes objetivos:

1) Determinação da condutividade hidráulica pelo método do perfil instantâneo, empregando: a) o procedimento sugerido por HILLEL et alii (1972), que foi considerado como método padrão; b) a modificação introduzida por CHO et alii (1977), denominado de método de HILLEL Modi dificado (1) e c) a modificação na determinaçäo do fluxo através de um processo analítico, que foi denominado método de HILLEL Modificado (II);

2) Estudo da variabilidade espacial da condutividade hidráulica na parcela experimental; 
.03.

3) Estudo da propagação de erros na determinação do valor mëdio da condutividade hidräulica. 
.04 .

\section{REVISAO DE LITERAT.URA}

DARCY (1856) trabalhando com colunas de areia saturada de água comprovou, atravēs de um permeâmetro de carga constante, que a quantidade de água que fluía por unidade de tempo e de área era proporcional ao gradiente hidrăulico, sendo a constante de proporcionalidade denominada condutividade hidrăulica. E um parâmetro específico de cada meio poro so e representa sua capacidade em transmitir água.

BUCK INGHAM (1907) adaptou a equação de DARंCY (1856) para condições de fluxos não saturado em solos, ajustando a condutividade hidräulica para o respectivo conteüdo de água do solo. RICHARDS (1931) com binou a equação de Darcy com a equação da continuidade e obteve a equação diferencial geral que descreve o movimento de água em solos. Posteriormente HILLEL (1970) tambëm mostrou a validade da equação de Darcy relacionando a condutividade hidráulica com o potencial matricial.

REICHARDT (1975) reconhece que as equações adaptadas por BUCKINGHAM (1907) e HILLEL (1970) são as que melhor descrevem o movimento 
da ägua no solo, embora sejam falhas para a linearidade das relações fluxo-gradiente quando o gradiente do potencial total apresenta valores muito altos ou muito baixos. Os trabalhos de HUBBERT (1956), SWARTZENDRUBER (1962), MILLER e LOW (1963) e KLUTE (1965) citados por REICHARDT (1975) apresentam detalhes da limitação do emprego destas equações. Devido a tais fatos é que diversos pesquisadores têm-se preocupado com a elaboração de métodos que mais se ajustem às condições reais com o fim de estimar de uma maneira mais precisa a condutividade hidráulica dos solos.

Os métodos existentes para a obtenção da condutividade hidräulica podem ser subdivididos em duas categorias: 1) Métodos experimentais de laboratório e de campo e 2) Métodos teóricos baseados em equações numéricas. Os métodos experimentais de laboratório elaborados por RICHARDS e WEEKS (1953), YOUNGS (1964), KLUTE (1965), REICHARDT et alii (1975) e outros têm sido mudados e adaptados para as condições de campo (RICHARDS et alii, 1956, NIELSEN et alii, 1961, ROSE et alii, 1965, LA RUE et alii, 1968, van BAVEL et ali i, 1968, DAVIDSON et alii, 1969, HILLEL et alii, 1972, NIELSEN et alii, 1973 e FLÜHLER et alii, 1976, entre outros). ROULIER et alii (1972) e BRUCE (1972) citam as equações numéricas de MARSHALL (1958), MILLINGTON e QUIRK (1959) e LALIBERTI et ali i (1966) cono procedimento para avaliação da condutividade hidräulica em condições de fluxo transiente.

As determinações experimentais da condutividade hidräulica em laboratório têm sido realizadas em grande escala. Entretanto, os pesquisadores são unânimes em afirmar que este procedimento é falho, pois 
uma simples amostra não representa as condições reais do solo, além de estar sujeita a alterações em slia estrutura durante a amostragem. Este fa to conduziu ao desenvolvimento de diversos mëtodos experimentais de campo. 0 método de drenagem transiente ou do perfil instantâneo tem se tornado um procedimento padrão na orientação do estudo do movimento de àgua no solo conforme os trabalhos realizados por ROSE et alii (1965), van BAVEL et alii. (1968), HILLEL et alii (1972), NIELSEN et alii (1973) e FLÜHLER et alii (1976).

HILLEL et alii (1972) apresentaram uma descrição detalhada do método de drenagem transiente tornando-o um procedimento mais simplificado. Este método exige a obtenção de perfís de umidade e do potencial matricial do solo para o cálculo da condutividade hidráulica. Os perfís de umidade são determinados satisfatoriamente e com vantagens através da técnica de moderação de neutrons (FERRAZ, 1972). Para a obtenção do potencial matricial usam-se tensiômetros de manômetro de mercūrio instalados a diversas profundidades (RICHARDS, 1965). BAKER et alii (1974) propõem uma nova tēcnica de instalação de tensiômetros.

REICHARDT e LIBARDI (1974) empregando a metodologia de HILLEL et alii (1972) obtiveram sucesso na determinação da condutividade hidräulica em três parcelas de Terra Roxa Estruturada do - município de Piracicaba (SP). Encontraram valores de condutividade hidräulica de 5 a $0,05 \mathrm{~cm} \mathrm{dia}^{-1}$ para uma variação do conteúdo de àgua do solo de 0,38 a $0,32 \mathrm{~cm}^{3} \cdot \mathrm{cm}^{-3}$.

Trabalhos desenvolvidos em locais diferentes, conduzidos por NIELSEN et alii (1973), CHO et alii (1975), HILLEL e van BAVEL (1976), 
FLUHLER et alii (1976), VERPLANCKE et alii (1977), MARINI et alii (1977), CHO et alii (1977) e outros mostraram resultados satisfatórios.

Um aspecto importante que tem despertado grande interesse na atualidade é a variabilidade espacial da condutividade hidráulica quando calculada através de medições de campo. BAKER et alii (1974) consideram que esta variabilidade é devido a características do pröprio perfil do solo e problemas técnicos.

NIELSEN et alii (1973) trabalhando com vinte parcelas experimentais instaladas numa ärea de 150 ha, fizeram um estudo comparativo da condutividade hidráulica de duas parcelas (de n?s 18 e 20) e constataram que fisicamente é sem sentido extrapolar a condutividade hidräulicada curva condutividade versus conteüdo de água no solo de uma parcela para outra. Isto porque em condições de equilíbrio o conteüdo de ägua da parcela 18 foi de $0,448 \mathrm{~cm}^{3} \cdot \mathrm{cm}^{-3}$ (igual a $100 \%$ da saturação), enquanto que para a parcela 20 o valor do conteúdo de água foi de $0,513 \mathrm{~cm}^{3} \cdot \mathrm{cm}^{-3}$ (igual a $94,8 \%$ da saturação). Assim, o conteúdo de àgua da parcela 18 nunca poderia exceder a $0,448 \mathrm{~cm}^{3} \cdot \mathrm{cm}^{-3}$ e como o da 20 nunca foi inferior a 0,460 $\mathrm{cm}^{3} \cdot \mathrm{cm}^{-3}$; torna-se impossível a manipulação destes dados para obtenção de valores médios de condutividade hidräulica que representem a ärea onde estão contidas as duas parcelas para um conteúdo de àgua específico.

Sabendo-se que a relação entre a condutividade hidräulica e o conteúdo de àgua do solo é uma função exponencial, deprende-se que uma pequena variação do conteūdo de àgua do solo implica numa grande variação da condutividade hidrāulica. Procurando superar esta dificuldade, 
NIELSEN et alii (1973) sugerem expressar a condutividade hidräulica em função da percentagem de saturação, isto porque a taxa de infiltração é altamente correlacionada com a percentagem de saturação, o que não ocorre com o conteúdo de água. Assim, elimina-se o problema de avaliação da variabilidade espacial da condutividade hidräulica ocasionada pelas variaf̧ões nas caracteristicas da água do solo.

REICHARDT et alii (1976) estudando a variabilidade espacial em três parcelas de $5 \mathrm{~m} \times 5 \mathrm{~m}$ instaladas em um Alfisol tiveram valores da condutividade hidräulica saturada de 5,$3 ; 10,0$ e $13,7 \mathrm{~cm} \cdot \mathrm{h}^{-1}$ para moda, mediana e média, respectivamente. Verificaram também uma grande variabilidade em torno do valor médio da condutividade hidräulica não saturada de um mesmo perfil de solo; constatando erros da ordem de grandeza de \pm 100 vezes. Daí, concluíram que este fato torna difícil a deter minação do fluxo de água do solo em condições de campo. Entretanto, FLÜHLER et alii (1976) admitem que esta magnitude dos erros envolvidos na estimativa deste parâmetro não sentencia o fracasso do método, e sim possibilita apreciar suas limitações.

A equação de Darcy permite calcular a condutividade hidrāulica pela relação entre a densidade de fluxo ( $(\Delta / \Delta t)$ e o gradiente de potencial $(\Delta \psi / \Delta Z)$; daí verifica-se que as causas principais de erros neste parâmetro são devidos às medidas de umidade e tensiômetros. FLüHLER et alii (1976) aplicando a técnica de anālise de erro multivariavel que expli clta por meio de equações o erro da função atravēs dos erros das variāveis (CLIFFOED, 1973) e do método de simulação de Monte Carlo (HAHN e SHAPIRo, 1967), constataram que os erros na variação do conteúdo de ãgua são signi 
ficativos quando a drenagem é lenta, devido a não saturação do solo,e que os erros provenientes da leitura de tensiômetros são significativos quando o valor do gradiente de potencial for inferior a $0,3 \mathrm{mBar} . \mathrm{cm}^{-1}$. Concluíram que em condições pröximas à saturação o erro apresentado pela con dutividade hidráulica varia de 20 a $30 \%$ e quando o seu valor é pequeno, os erros relativos podem ser superiores a 100\%. Finalmente, admi tem que a predição dos erros para a condutividade hidráulica, a partir das equações de propagação, são estimados num mínimo otimista.

MARINI et alii. (1977) estudando as propriedades hidrodinâmicas dos principais solos de Morandava-Madagascar, verificaram que nos solos com mais de $80 \%$ de areia, uma variação de $3 \%$ no conteúdo de água do solo condicionava uma varią̧ão de 4,5 vezes no valor da condutividade hidräulica, quando o fluxo de água no solo se tornava lento e em solos arenosos com menos de $80 \%$ de areia, 5,5 vezes. 


\section{MATERIAIS E METODOS}

\subsection{Descrição geral da area}

0. presente trabalho foi instalado próximo ao Posto Meteorológico do Dẹpartamento de Física e Meteorologia, situado no Campus Expe rimental da Escola Superior de Agricultura "Luiz de Queiroz",com uma ärea de aproximadamente 10 ha. 0 local se encontra a uma altura de $580 \mathrm{~m}$ acima do nivel do mar com coordenadas geogräficas de $22^{\circ} 42^{\prime} 30^{\prime \prime} S$ de latitude e $47^{\circ} 38^{\prime} 00^{\prime \prime} \mathrm{W}$ de longitude. Apresenta uma caracterização elimätica média anual de $1.247 \mathrm{~mm}$ de precipitação normal, $20,8^{\circ} \mathrm{C}$ de temperatura e $69 \%$ de umidade relativa.

Segundo o levantamento da Carta de Solos de Piracicaba (RANZANI et alii, 1966), o solo desta ärea pertence ao grande grupo Ter ra Roxa Estruturada, classificado de acordo com a 7a. aproximação como um ultic Ultustalf. A caracterização física de um perfil típico do solo da área em estudo é mostrada na Tabela n̊ l. 
Tabela 1 - Caracterização física do solo Terra Roxa Estruturada.

\begin{tabular}{cccccc}
\hline $\begin{array}{c}\text { Profundidade } \\
(\mathrm{cm})\end{array}$ & $\begin{array}{c}\text { Densidade } \\
\text { global } \\
(-)\end{array}$ & $\begin{array}{l}\text { Composição granulométrica } \\
\end{array}$ & \% Argila $\%$ & Limo $\%$ Areia & $\begin{array}{c}\text { Classe } \\
\text { textural }\end{array}$ \\
\hline $0-30$ & 1,31 & 60 & 17 & 23 & Argila \\
$30-60$ & 1,35 & 63 & 23 & 14 & Argila \\
$60-90$ & 1,20 & 55 & 26 & 19 & Argila \\
$90-120$ & 1,18 & 52 & 26 & 22 & Argila \\
$120-150$ & 1,11 & 54 & 24 & 22 & Argila \\
$150-180$ & 1,14 & 49 & 28 & 23 & Argila \\
\hline
\end{tabular}

\subsection{Medições a campo}

\subsubsection{Parcela experimental}

0 experimento foi instalado numa àrea sistematizada a nivel com dimensões de $10 \mathrm{~m} \times 10 \mathrm{~m}$, considerada suficientemente grande, a ponto de evitar que os processos em seu centro não sejam influenciados pelos seus limites (HILLEL et alii, 1972).

\subsubsection{Condutividade hidrāulica saturada}

A parcela experimental foi inundada durante 24 horas, mantendo-se na superfície uma lâmina de ägua de aproximadamente $10 \mathrm{~cm}$. Apōs 
este período, e verificado a condição de infiltração em equilibrio dinâmi co (steady state), instalaram-se cilindros de plástico de $30 \mathrm{~cm}$ de diàmetro em dois locais da parcela. Com uma escala graduada mediu-se a altura da lâmina de ägua infilttrada para um determinado intervalo de tempo,obten do-se assim a condutividade hidräulica saturada.

\subsubsection{Condutividade hidrāutica não saturada}

Para a obtenção de dados de condutividade hidrāulica não saturada instalaram-se tensiômetros e tubos de acesso para receber a sonda de neutrons na parcela experimental. Visando evitar a evaporação na superfície do solo e impedir a entrada de qualquer forma de ocorrência de água na parcela, esta foi coberta com plästico após a determinação da con dutividade hidräulica saturada.

\subsubsection{Tensiōmetros}

Instalaram-se vinte tensiômetros de manômetro de mercürio, sendo dez a $105 \mathrm{~cm}$ de profundidade e dez a $135 \mathrm{~cm}$. Os manômetros oride se realizavam as leituras dos tensiômetros foram colocados em uma única cuba de mercürio a $45 \mathrm{~cm}$ da superfície do solo e condicionados em um abri go fora da parcela. 


\subsubsection{Tubos de acesso}

A Figura I mostra os locais onde foram instalados os quatro tubos de alumínio para dar acesso à sonda de neutrons. A profundida de atingida pelos tubos foi superior a $120 \mathrm{~cm}$ para possibilitar medições do conteúdo de àgua do solo até esta profundidade.

\subsubsection{Sonda de neutrons}

A sonda de neutrons utilizada foi construída pela NORDISK ELEKTRISK APARATFABRIK, COPENHAgEN, Denmiark, Model Basc Depth Moisture/Den site Probe. As curvas de calibração de umidade deste equipamento para di ferentes valores de densidade global do solo em estudo, foram elaboradas por REICHARDT E LIBARDI (1974).

\subsection{Metodologia}

\subsubsection{Condutividade hidrāulica não saturada}

\subsubsection{Base teōrica}

A capacidade de um solo em transmitir água a um certo teor de umidade é conhecida como condutividade hidrāulica. A equação de Darcy mostra que esta propriedade do solo è um fator de proporcionalidade:

$$
q=-k(\theta) \frac{\partial \psi}{\partial z} \ldots \ldots \ldots \ldots
$$



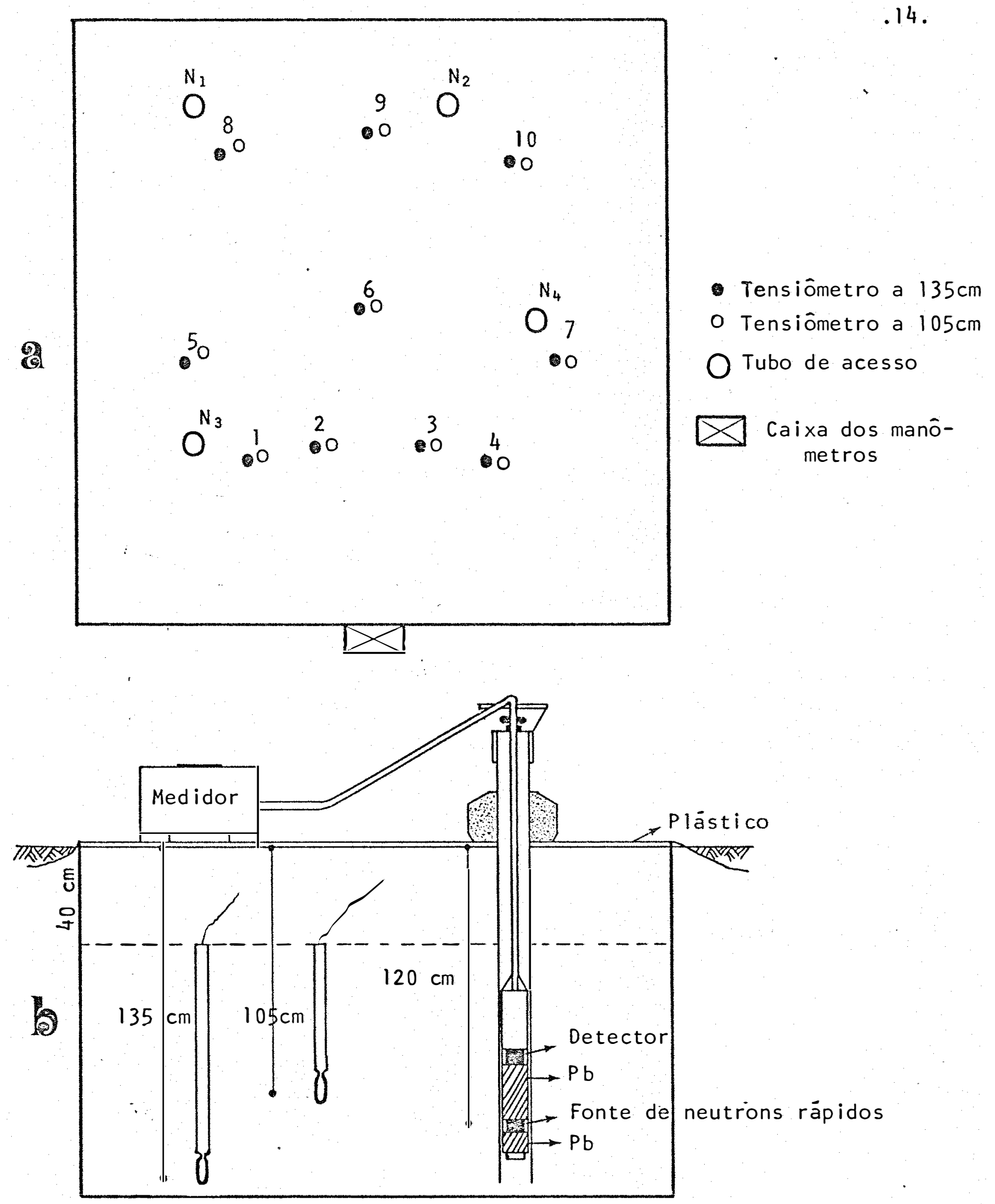

Figura 1 - Parcela Experimental. a) Vista de planta indicando posição dos. tensiómetros $(T)$ e Tubos de acesso $(N)$; b) Corte transversal apresentando detalhes de instalação dos tensiômetros e da sonda de neutrons. 
.15.

onde:

$$
\begin{aligned}
& q=\text { densidade de fluxo }\left[L^{3} \cdot L^{-2} T^{-1}\right] \text {. } \\
& K(\theta)=\text { condutividade hidrāulica do solo }\left[L T^{-1}\right] \text { a qual è fun- } \\
& \psi=\text { Potencial total da água do solo [L], o qual representa, } \\
& \text { para um fluxo vertical, a soma dos potenciais matri- } \\
& \text { cial }(\xi) \text { e gravitacional }\left(\psi_{\mathrm{G}}\right) \text {. } \\
& z=\text { Coordenada vertical da posição }[L] \text {. } \\
& \text { Combinando a equação de Darcy com a equação da continuidade, } \\
& \frac{\partial \theta}{\partial t}=-\frac{\partial q}{\partial z}, \ldots \ldots \ldots \ldots \ldots
\end{aligned}
$$

onde:

$$
\begin{aligned}
\frac{\partial \theta}{\partial t}= & \text { representa a variação do conteūdo de ägua do solo com } \\
& \text { o tempo em dada profundidade } e,
\end{aligned}
$$

$$
\begin{aligned}
\frac{\partial q}{\partial z}= & \text { variação do fluxo com a distância, em um dado instan- } \\
& \text { te, obtēm-se a equação diferencial mais geral para o } \\
& \text { fluxo de água no solo na direção vertical: }
\end{aligned}
$$

$$
\frac{\partial \theta}{\partial t}=\frac{\partial}{\partial z}\left[K(\theta) \frac{\partial \psi}{\partial z}\right] \ldots . . . . . . . . . .
$$

onde, $\theta$ e $\psi$ são expressados por uma função de $z$ e $t$, ou seja, $\theta=\theta(z, t)$ e $\psi=\psi(z, t)$. 


\subsubsection{Método de HILLEL et alii (1972)}

0 procedimento sugerido por HILLEL et alii (1972) pode ser aplicado até em perfís de solos heterogêneos sendo limitado apenas para solos onde o lençol freático se encontra pröximo à superfície. Atingida a condição de infiltração em equilibrio dinâmico, indicada pela leitura dos tensiômetros, deixa-se a àgua infiltrar-se por completo na superfície do solo e cobre-se a mesma com plástico para evitar evaporação. A água conti da no perfíl se redistribui pelo processo de drenagem interna e periodica mente medidas de umidade do solo e de potencial da água são realizadas.

Nestas condições, integrando-se a equação (3) com relação a $z$, da superficie do solo a uma profundidade h qualquer, obtëm-se:

$$
\int_{0}^{h} \frac{\partial \theta}{\partial t} d z=\left[k(\theta) \frac{\partial \psi}{\partial z}\right]_{0}^{h} \cdots \ldots . . . \cdots
$$

ou, considerando $\partial \theta / \partial t$ independente de $z$,

$$
\left[\frac{\partial \theta}{\partial t}\right] \cdot h=\left[k(\theta) \frac{\partial \psi}{\partial z}\right]_{z=h}-\left[k(\theta) \frac{\partial \psi}{\partial z}\right]_{z=0} \ldots \ldots
$$

Como a superfície do solo foi revestida com plástico, conclui-se que na profundidade $z=0$, o fluxo è nulo e a equação (5) fica re duzida a:

$$
\left(\frac{\partial \theta}{\partial t}\right) \cdot h=\left[k(\theta) \frac{\partial \psi}{\partial z}\right]_{z=h} \ldots \ldots \ldots
$$

0 primeiro membro da equação (6) representa a densidade de fluxo $(-q)$ que atinge a profundidade $h$ (podendo ser obtido integrando-se 
sucessivos perfis de umidade até o plano $z=h$ ). Assim, substituindo 0 valor de -q na equação (6) e reajustando-a, obtém-se:

$$
K(\theta)=-\frac{q}{\partial \psi / \partial z} \cdot \ldots \cdot \cdots \cdot \ldots \cdot \ldots \cdot \ldots
$$

que permite calcular o valor de $K(\theta)$, pois a densidade de fluxo $(-q)$ e o gradiente de potencial $(\partial \psi / \partial z)$ podem ser obtidos pela técnica de moderação de neutrons e por tensiômetros, respectivamente. Para a obtenção da densidade de fluxo, mede-se a cada intervalo de tempo, a umidade do perfil do solo e atravēs de tensiômetros instalados às profundidades esta belecidas determina-se o potencial matricial da āgua do solo e daí o gradiente de potencial total.

\subsubsection{Método de HILLEL Modificado (I)}

CHO et alii (1977) propõem uma modificação na metodologia de HILLEL e seus colaboradores, visando tornar mais räpido e simplificado o cälculo da condutividade hidräulica de um perfil de drenagem transiente.

Assim, o primeiro membro da equação (6), descrita no método de HILLEL et alii (1972) que representa o somatōrio das variações da umidade com o tempo na profundidade de $0-h$, corresponde ao armazenamento (W) entre dois tempos consecutivos para a referida camada, pois,

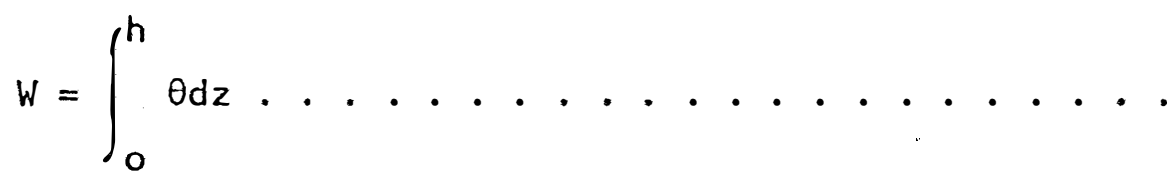


o que permite escrever a seguinte formulação:

.18 .

$$
\frac{\partial \theta}{\partial t} \cdot h=\left[\frac{d W}{d t}\right]_{z=h}=-q=\left[K(\theta) \frac{\partial \psi}{\partial z}\right]_{z=h} \ldots . .
$$

Reajustando-se a equação (9) tem-se que:

$$
K(\theta)=-\frac{\frac{d w}{d t}}{\frac{\partial \psi}{\partial z}} \ldots \ldots \ldots \ldots
$$

0 termo dW/dt pode ser obtido graficamente a partir de per fís de umidade durante o tempo de redistribuição da água e $\partial \psi / \partial z$ através de tensiômetros, como foi visto anteriormente, e assimobter-se o valor de condutividade hidráulica pela equação (10).

\subsubsection{Método de HILLEL Modificado (II)}

Tem-se verificado que um dos problemas que normalmente ocor remnadeterminação da condutividade hidráulica pelos dois métodos descritos, decorre da dificuldade de se obter corretamente as tangentes dos gráficos de $\theta$ versus $t$ ou $W$ versus $t$.

Para solucionar o problema sugere-se a constrlição de gräficos de umidade ou de armazenamento versus logaritmo do tempo possibilitando assim o cálculo da densidade de fluxo analiticamente. Isto será pos sivel desde que se encontre uma solução analítica para a dependência entre $\theta$ ou W e t. 
Admitindo a hipótese que os pontos se distribuam segundo uma reta com um al to coeficiente de correlação, um grăfico de armazenamento versus logarítmo do tempo será representado pela equação:

$$
w=a-b l n t \ldots \ldots \ldots . \ldots . \ldots
$$

onde,

$$
\begin{aligned}
& W=\text { armazenamento da água do solo }\left[\mathrm{L}^{-} \mathrm{L}\right] . \\
& \mathrm{a}=\text { coeficiente linear. } \\
& \mathrm{b}=\text { coeficiente angular. } \\
& \mathrm{t}=\text { tempo }[\mathrm{T}] .
\end{aligned}
$$

Calculando-se a primeira derivada da equação (11) com relação ao tempo, tem-se:

$$
\frac{d W}{d t}=-\frac{b}{t} \ldots \ldots \ldots \ldots \ldots
$$

Como a densidade de fluxo q corresponde a $\frac{d W}{d t}$, depreende-se que seu valor pode ser calculado analiticamente pela equação (12).

Procedimento similar poderá ser feito para um grä́fico de umidade versus logarítmo do tempo.

\subsubsection{Propagação de erros}

As fontes de erro que normalmente ocorrem na determinação 
da condutividade hidräulica a campo são provenientes de: 19) Variação espacial do movimento da àgua devido às condições intrínsecas do prōprio solo; 2:) Erros de campo, causados pela precisão e instalação dos equipamentos e leituras realizadas e 3?) Erros de aproximação provenientes da interpolação, modificando os erros de observação.

Para identificação da variabilidade espacial dentro da par cela, instalaram-se quatro tubos de acesso em locais diferentes (Figura l) e uma mëdia de 2 a 3 tensiōmetros por profundidade pröximo a cada tubo. Isto permite o cálculo da condutividade hidráulica em quatro locais da parcela, possibilitando determinar-se o valor médio deste parâmetro e sua variabilidade espacial pelos três métodos estudados.

Procurando atenuar a dificuldade de avaliar a variabilidade espacial da condutividade hidrāulica em função do conteúdo de ãgua do solo, estimou-se este parâmetro em função da umidade de saturação atra vēs da equação:

$$
k(\theta)=k_{0} \exp \alpha\left(\theta_{0}-\theta\right) \ldots . . . . . . . .
$$

onde,

$$
\begin{aligned}
k_{0}= & \text { condutividade hidräulica saturada. } \\
\theta_{0}= & \text { conteüdo de água em volume do solo quando saturado em } \\
& \text { condições de campo. } \\
\alpha= & \text { coeficiente angular. }
\end{aligned}
$$

A estimativa das outras duas fontes de erros foi feita con juntamente utilizando-se as expressões indicadas por CHASE e RABINOWITZ 
(1967): Estas expressões são empregadas para as operações matemāticas simples que incluem erros e possibilitam sua manipulação separadamente e de uma maneira distinta. Assim, considerando duas quantidades $A$ e $B$ que incluem erros a e t respectivamente, dependendo do tipo de operação matemática envolvida, seus erros podem assim serem calculados:

ADIÇÃo: $\quad(A \pm a)+(B \pm b)=(A+B) \pm \sqrt{a^{2}+b^{2}} \ldots . . . . . .(14)$

SUBTRAÇÃO. $\quad(A \pm a)-(B \pm b)=(A-B) \pm \sqrt{a^{2}+b^{2}} \ldots \ldots$ (15)

MULTIPLICAÇAO: $(A \pm a)(B \pm b)=(A B)\left(1 \pm \sqrt{a^{2} / A^{2}+b^{2} / B^{2}}\right) \ldots \ldots(16)$

DIVISÃO: $\quad(A \pm a):(B \pm b)=(A / B)\left(1 \pm \sqrt{a^{2} / A^{2}+b^{2} / B^{2}}\right) \ldots$ (17) 
4. RESULTADOS E DISCUSSAOO

4.1. Condutividade hidrāulica saturada

Os testes de infiltração realizados em parcela experimental possibilitaram a obtenção de um valor médio da condutividade saturada de $10,56 \mathrm{~cm} \mathrm{dia}^{-1}$. Este valor quando comparado com o obtido por REICHARDT e LIBARDI (1974), que trabalharam neste mesmo solo, apresenta-se bastante inferior, ou seja, cinco vezes menor. Esta diferença è admissivel, uma vez que os locais de amostragem foram distintos, e isto permite admitir uma variabilidade das caracteristicas físico-hídricas da ärea experimental.

4.2. Condutividade hidrāulica não saturada

Basicamente este trabalho foi desenvolvido em função dos dados obtidos a campo, que se encontram nas Tabelas 2 e 3 . A Tabela 2 mos tra os valores da variação do conteüdo de àgua do solo ãs profundidades de $30,60,90$ e $120 \mathrm{~cm}$ com o tempo para os locais onde foram instalados os quatro tubos de acesso ao acaso na parcela, enquanto que a Tabela 3 


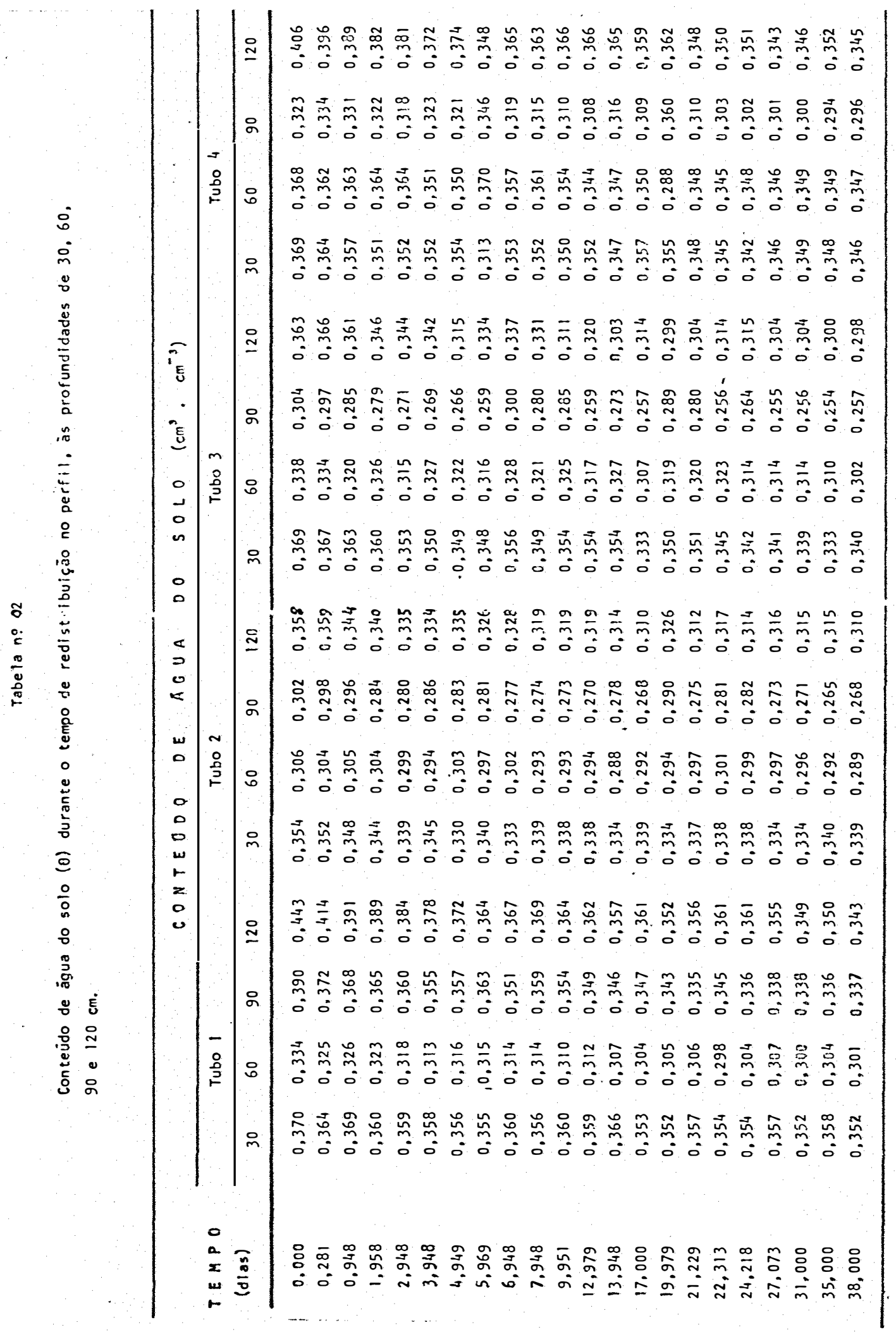




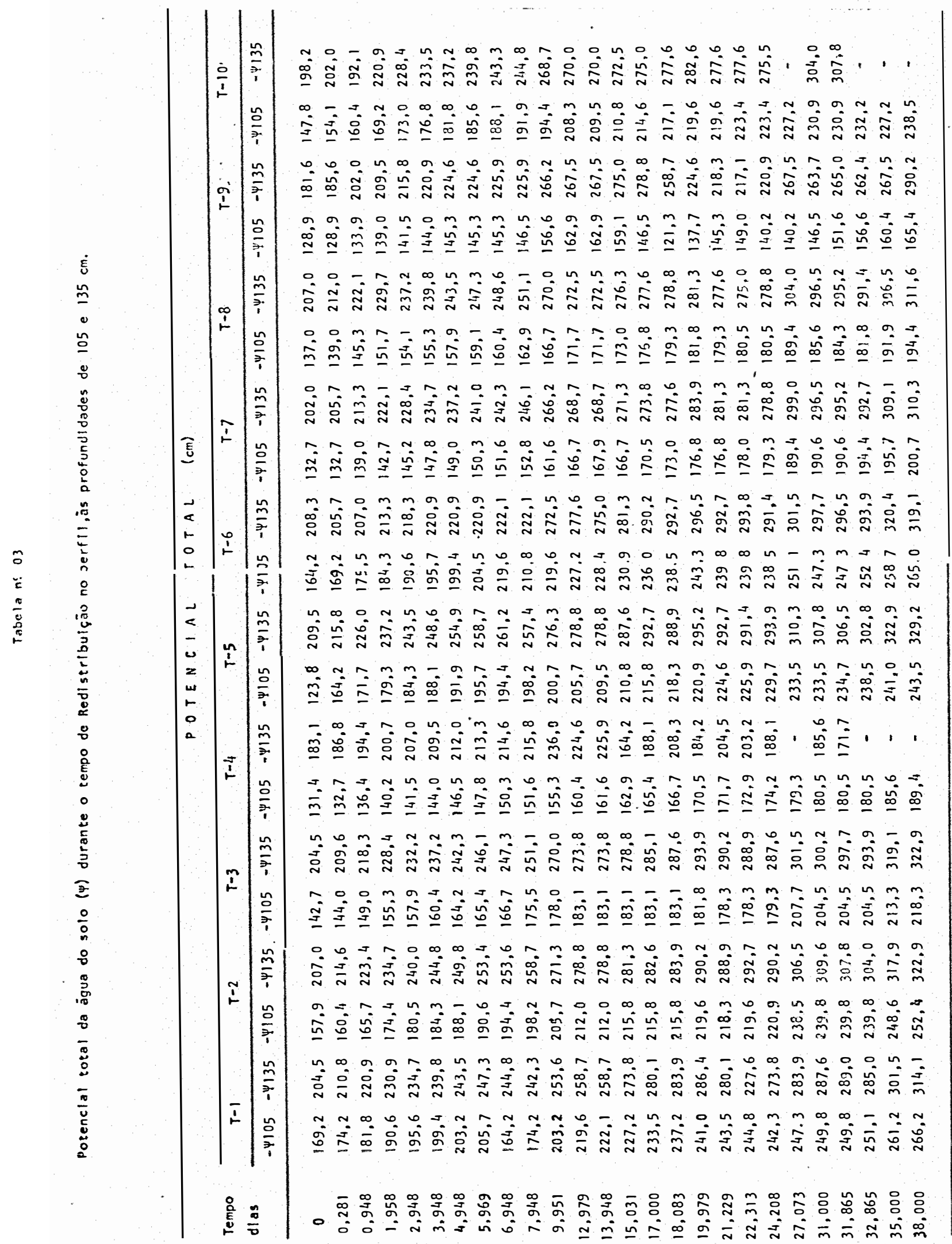


apresenta a variação dos valores do potencial total da água do solo às profundidades de 105 e $135 \mathrm{~cm}$ com o tempo, nos locais dos vinte tensiómetros instalados.

4.2.1. Mētodo de HILLEL et a7ii (1972)

As Figuras $2,3,4$ e 5 representam as curvas de variação do conteúdo de água do solo com o tempo, nos quatro locais de instalação dos tubos de acesso, para as profundidades de $30,60,90$ e $120 \mathrm{~cm}$, respectivamente. Para a obtenção destas figuras plotaram-se os pontos de umidade para os respectivos tempos e traçou-se a curva que mais se adapta va aos pontos. A partir das Figuras $2,3,4$ e 5 construiram-se as curvas da Figura 6 que representam a variação média do conteüdo de ägua do solo com o tempo na parcela, para as quatro profundidades $(30,60,90$ e $120 \mathrm{~cm})$. Ressalte-se que os valores de umidade plotados nas curvas da Fi gura 6 foram determinados extraindo-os das quatro curvas correspondentes a uma profundidade e calculando-se um valor médio para um determinado tem po. Da Figura 6 confeccionou-se a Tabela 4 que apresenta valores médios da densidade de fluxo das camadas $0-45,45-75,75-105$ e $105-120 \mathrm{~cm}$ durante o processo de redistribuição da āgua do solo para o período de tempo considerado ( 0 a 40 dias). Os valores $\frac{\partial \theta}{\partial t}$ foram obtidos estimando-se tangentes às curvas da umidade versus tempo nas diversas profundidades e diversos tempos. 


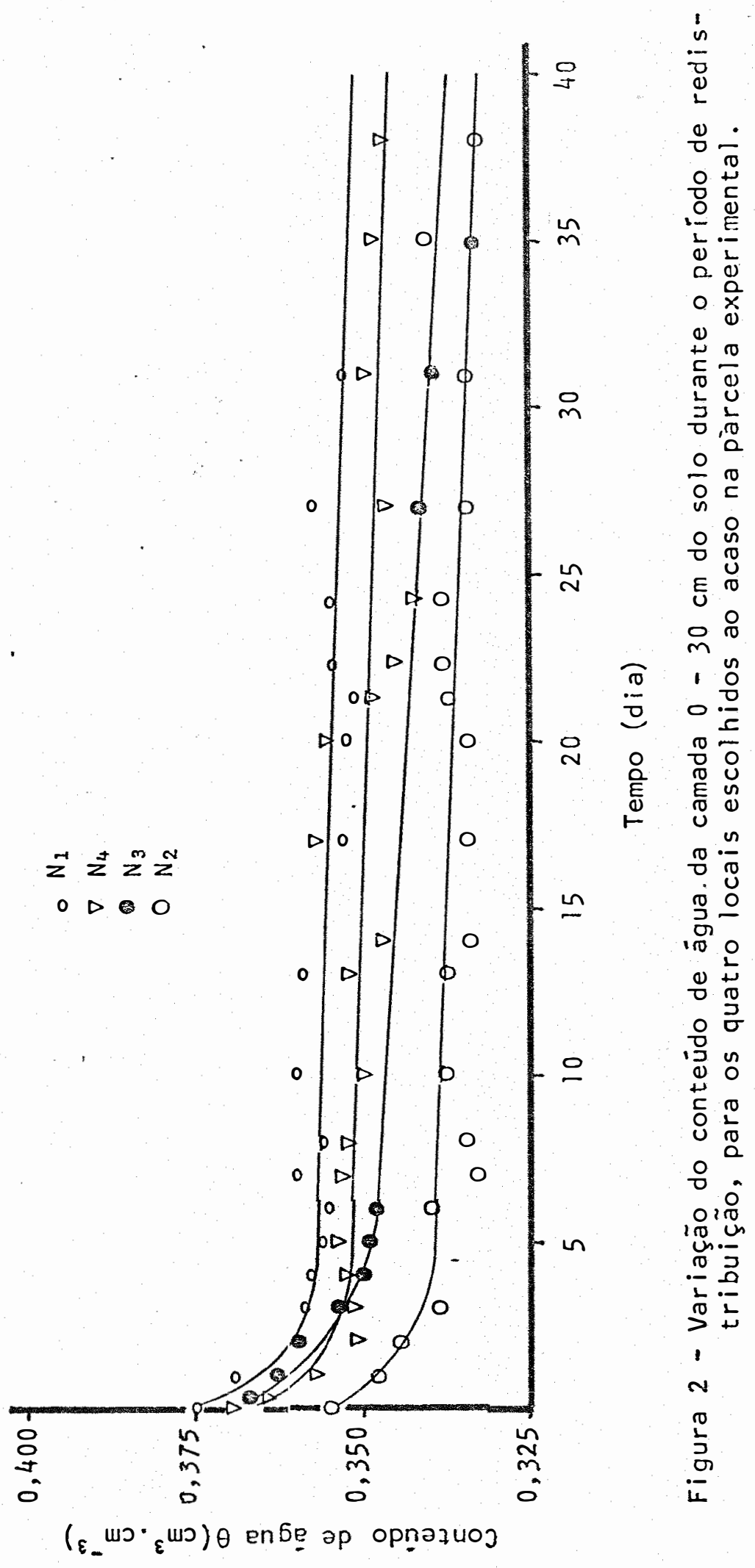




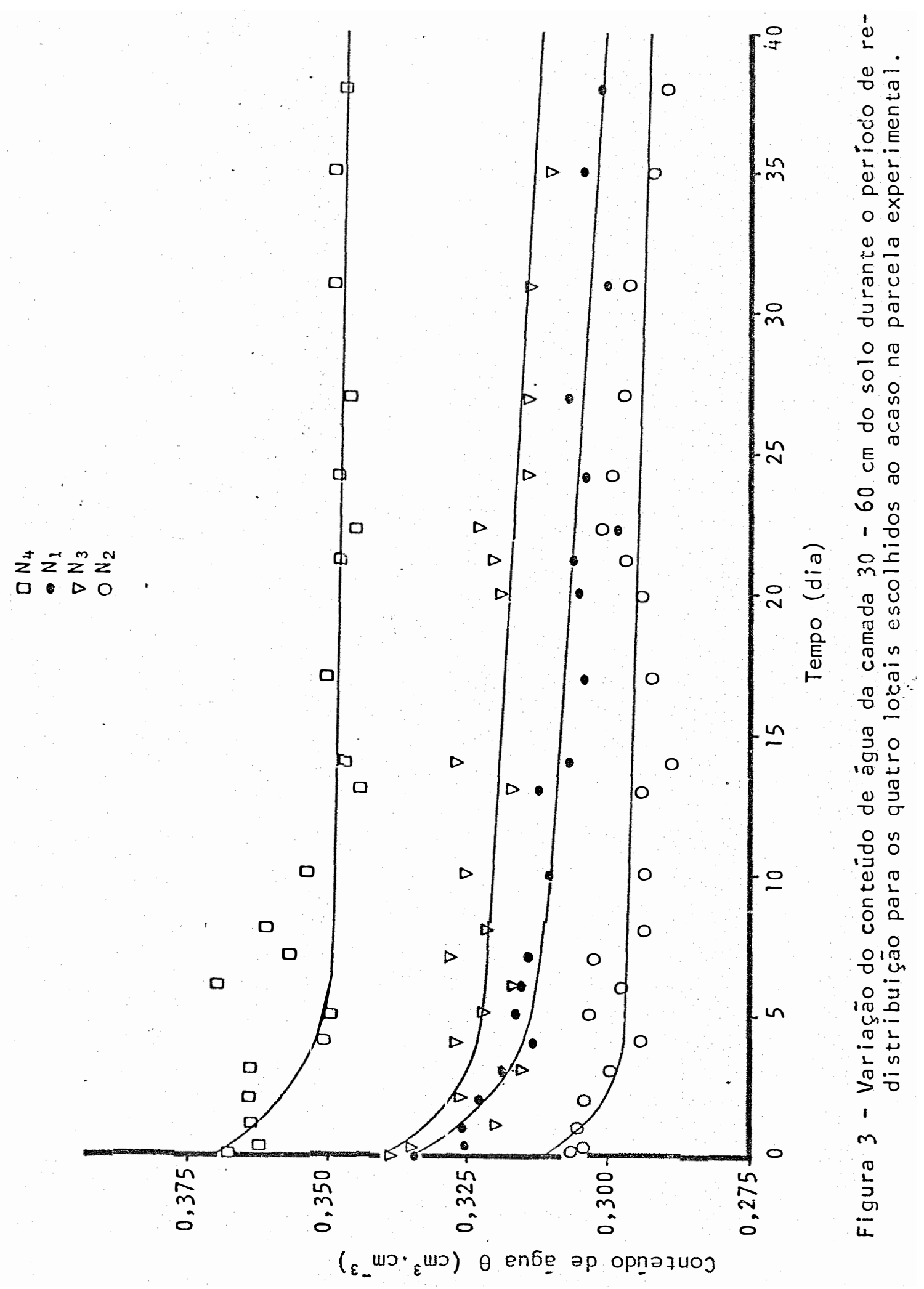


.28

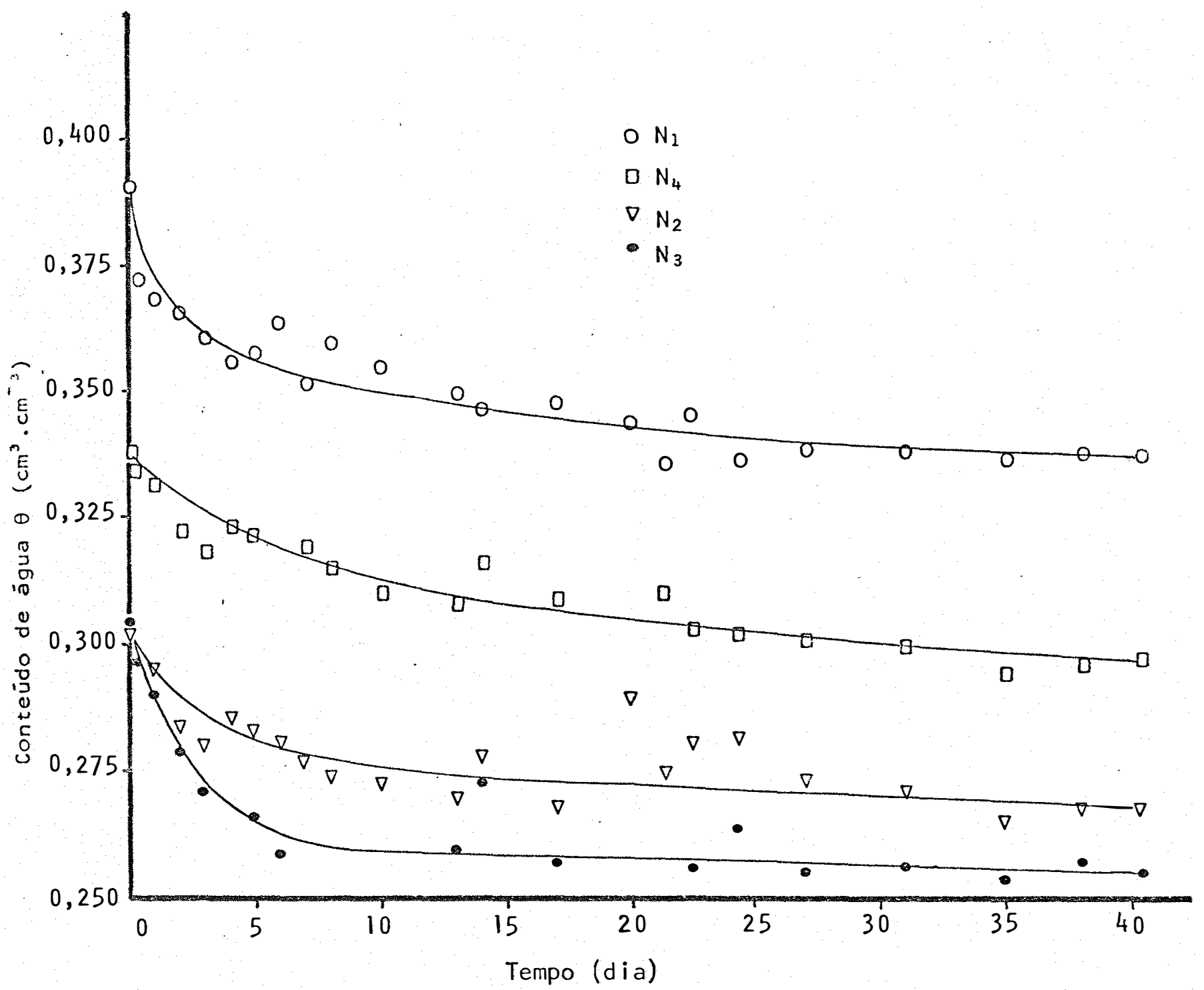

Figura 4 - Variação do conteūdo de água da camada 60 - $90 \mathrm{~cm}$ do solo durante o período de redistribuição para os quatro pontos escolhidos ao acaso na parcela experimental. 


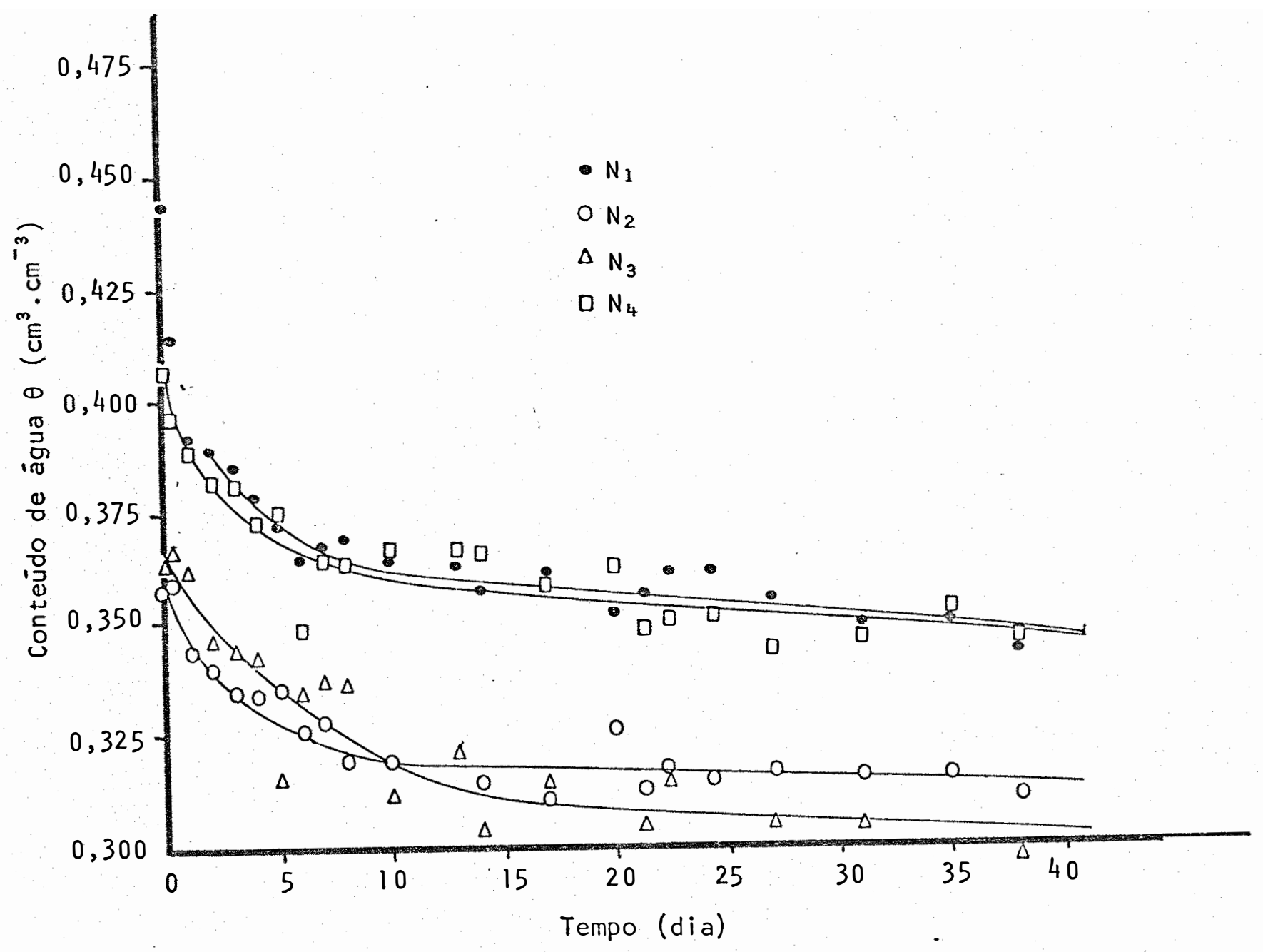

Figura 5. - Variação do conteúdo de água da camada $90-120 \mathrm{~cm}$ do solo durante o período de redistribuição para os quatro locais escolnidos ao aca so na parcela experimental. 


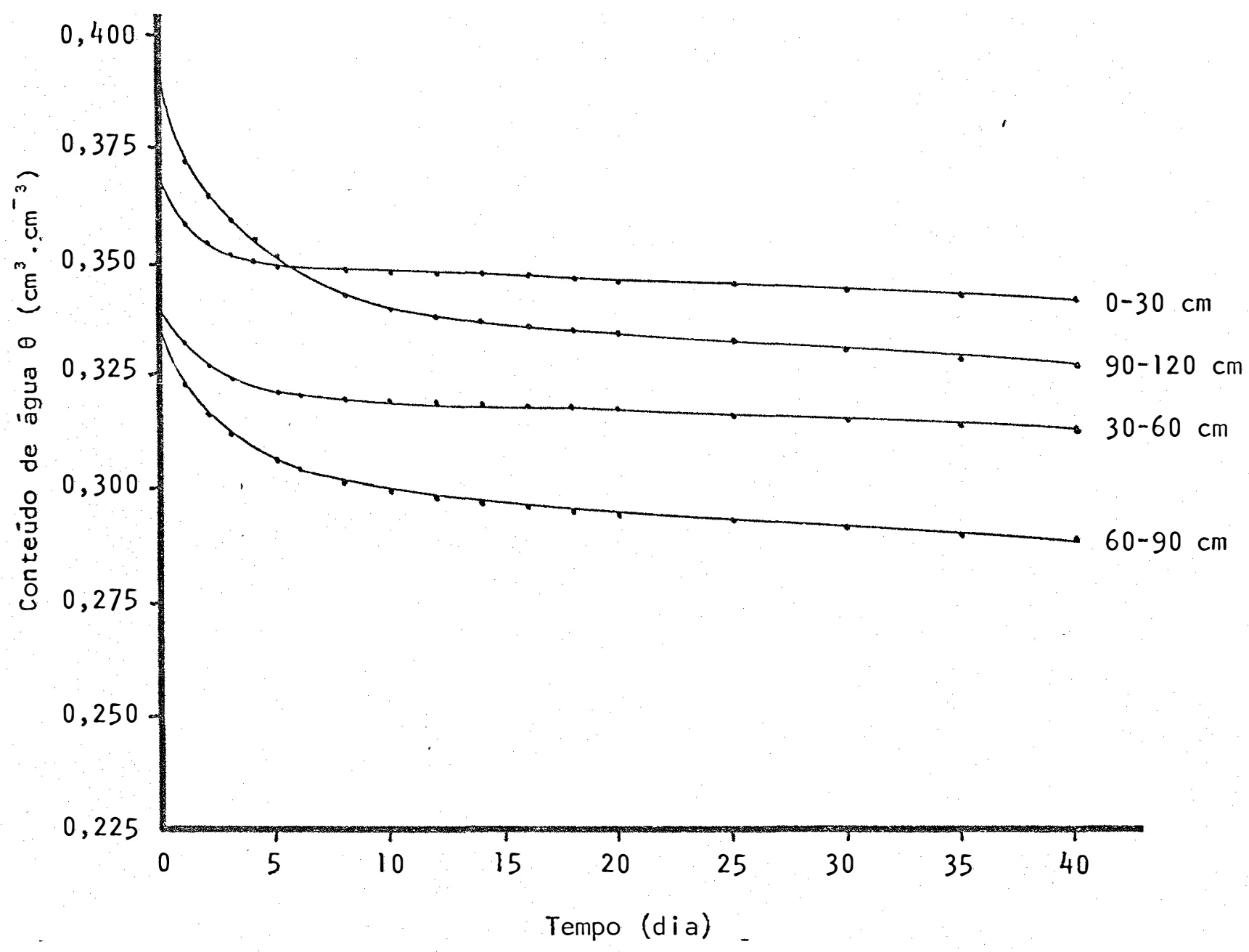

Figura 6 - Variação média do conteüdo de ãgua do solo durante o período de redistribuição nas camadas de $0-30,30-60,60-90$ e $90-120 \mathrm{~cm}$. 
Tabela n? 04

Valores médios da densidade de fluxo (q) da āgua do solo às diversas profun didades $(Z)$ e diversos tempos ( $t$ ). (Método de HILLEL et alii, 1972).

\begin{tabular}{|c|c|c|c|c|c|c|}
\hline $\begin{array}{c}t \\
(d i a)\end{array}$ & & & & $\frac{-\frac{\partial \theta}{\partial t}}{\left(\mathrm{~cm}^{3} \cdot \mathrm{cm}^{3} \cdot \mathrm{dia}^{-1}\right)}$ & $\begin{array}{r}-d z\left(\frac{\partial \theta}{\partial t}\right) \\
c m \cdot d i a^{-1}\end{array}$ & $\begin{array}{r}-\sum d z(\partial \theta / \partial t) \\
\left(\mathrm{cm} \cdot \mathrm{dia}{ }^{-1}\right)\end{array}$ \\
\hline$i$ & $\begin{array}{r}0 \\
45 \\
75 \\
105\end{array}$ & & $\begin{array}{r}45 \\
75 \\
105 \\
120\end{array}$ & $\begin{array}{l}0,0053 \\
0,0056 \\
0,0072 \\
0,0113\end{array}$ & $\begin{array}{l}0,2385 \\
0,1680 \\
0,3160 \\
0,1695\end{array}$ & $\begin{array}{l}0,2385 \\
0,4065 \\
0,6225 \\
0,7920\end{array}$ \\
\hline 2 & $\begin{array}{r}0 \\
45 \\
75 \\
105\end{array}$ & $\begin{array}{l}- \\
-\end{array}$ & $\begin{array}{r}45 \\
75 \\
105 \\
120\end{array}$ & $\begin{array}{l}0,0030 \\
0,0039 \\
0,0051 \\
0,0061\end{array}$ & $\begin{array}{l}0,1350 \\
0,1170 \\
0,1530 \\
0,0915\end{array}$ & $\begin{array}{l}0,1350 \\
0,2620 \\
0,4050 \\
0,4965\end{array}$ \\
\hline 3 & $\begin{array}{r}0 \\
45 \\
75 \\
105\end{array}$ & $\overline{-}$ & $\begin{array}{r}45 \\
75 \\
105 \\
120\end{array}$ & $\begin{array}{l}0,0018 \\
0,0025 \\
0,0039 \\
0,0044\end{array}$ & $\begin{array}{l}0,0810 \\
0,0750 \\
0,1170 \\
0,0660\end{array}$ & $\begin{array}{l}0,0810 \\
0,1560 \\
0,2730 \\
0,3390\end{array}$ \\
\hline 4 & $\begin{array}{r}0 \\
45 \\
75 \\
105\end{array}$ & $\begin{array}{l}- \\
-\end{array}$ & $\begin{array}{r}45 \\
75 \\
105 \\
120\end{array}$ & $\begin{array}{l}0,0012 \\
0,0015 \\
0,0030 \\
0,0039\end{array}$ & $\begin{array}{l}0,0540 \\
0,0450 \\
0,0900 \\
0,0585\end{array}$ & $\begin{array}{l}0,0540 \\
0,0990 \\
0,1890 \\
0,2475\end{array}$ \\
\hline 5 & $\begin{array}{r}0 \\
45 \\
75 \\
105\end{array}$ & $\begin{array}{l}- \\
- \\
-\end{array}$ & $\begin{array}{r}45 \\
75 \\
105 \\
120\end{array}$ & $\begin{array}{l}0,0007 \\
0,0008 \\
0,0020 \\
0,0035\end{array}$ & $\begin{array}{l}0,0315 \\
0,0240 \\
0,0600 \\
0,0525\end{array}$ & $\begin{array}{l}0,0315 \\
0,0555 \\
0,1155 \\
0,1680\end{array}$ \\
\hline 6 & $\begin{array}{r}0 \\
45 \\
75 \\
105\end{array}$ & $\begin{array}{l}- \\
- \\
-\end{array}$ & $\begin{array}{r}45 \\
75 \\
105 \\
120\end{array}$ & $\begin{array}{l}0,0004 \\
0,0006 \\
0,0017 \\
0,0031\end{array}$ & $\begin{array}{l}0,0180 \\
0,0180 \\
0,0510 \\
0,0465\end{array}$ & $\begin{array}{l}0,0180 \\
0,0360 \\
0,0870 \\
0,1335\end{array}$ \\
\hline 8 & $\begin{array}{r}0 \\
45 \\
75 \\
105\end{array}$ & $\begin{array}{l}- \\
- \\
-\end{array}$ & $\begin{array}{l}45 \\
75 \\
105 \\
120\end{array}$ & $\begin{array}{l}0,0002 \\
0,0003 \\
0,0011 \\
0,0021\end{array}$ & $\begin{array}{l}0,0090 \\
0,0090 \\
0,0330 \\
0,0315\end{array}$ & $\begin{array}{l}0,0090 \\
0,0180 \\
0,0510 \\
0,0825\end{array}$ \\
\hline
\end{tabular}


Tabela ne 04 (cont.)

\begin{tabular}{|c|c|c|c|c|c|}
\hline $\begin{array}{c}t \\
(d i a)\end{array}$ & & $\begin{array}{c}\text { z } \\
\mathrm{cm})\end{array}$ & $\left(\mathrm{cm}^{3} \cdot \mathrm{cm}^{-\frac{\partial \theta}{3}} \cdot \mathrm{dia}^{-1}\right)$ & $\begin{array}{r}-d z\left(\frac{\partial \theta}{\partial t}\right) \\
\quad c m \cdot d i a^{-1}\end{array}$ & $\begin{array}{r}-\sum d z\left(\partial \theta / \partial t^{2}\right) \\
\left(\mathrm{cm} \cdot d i a^{1}\right)\end{array}$ \\
\hline 10 & $\begin{array}{r}0 \\
45 \\
75 \\
105\end{array}$ & $\begin{array}{l}-\quad 45 \\
-\quad 75 \\
-\quad 105 \\
-\quad 120\end{array}$ & $\begin{array}{l}0,0002 \\
0,0002 \\
0,0007 \\
0,0013\end{array}$ & $\begin{array}{l}0,0090 \\
0,0060 \\
0,0210 \\
0,0195\end{array}$ & $\begin{array}{l}0,0090 \\
0,0150 \\
0,0360 \\
0,0555\end{array}$ \\
\hline 12 & $\begin{array}{r}0 \\
45 \\
75 \\
105\end{array}$ & $\begin{array}{r}-\quad 45 \\
-\quad 75 \\
-\quad 105 \\
-\quad 120\end{array}$ & $\begin{array}{l}0,0002 \\
0,0002 \\
0,0006 \\
0,0008\end{array}$ & $\begin{array}{l}0,0090 \\
0,0060 \\
0,0180 \\
0,0120\end{array}$ & $\begin{array}{l}0,0090 \\
0,0150 \\
0,0330 \\
0,0450\end{array}$ \\
\hline 14 & $\begin{array}{r}0 \\
45 \\
75 \\
105\end{array}$ & $\begin{array}{r}-\quad 45 \\
-\quad 75 \\
-\quad 105 \\
-\quad 120\end{array}$ & $\begin{array}{l}0,0002 \\
0,0002 \\
0,0005 \\
0,0006\end{array}$ & $\begin{array}{l}0,0090 \\
0,0060 \\
0,0150 \\
0,0090\end{array}$ & $\begin{array}{l}0,0090 \\
0,0150 \\
0,0300 \\
0,0390\end{array}$ \\
\hline 16 & $\begin{array}{r}0 \\
45 \\
75 \\
105\end{array}$ & $\begin{array}{l}-\quad 45 \\
-\quad 75 \\
-\quad 105 \\
-\quad 120\end{array}$ & $\begin{array}{l}0,0002 \\
0,0002 \\
0,0004 \\
0,0004\end{array}$ & $\begin{array}{l}0,0090 \\
0,0060 \\
0,0120 \\
0,0060\end{array}$ & $\begin{array}{l}0,0090 \\
0,0150 \\
0,0270 \\
0,0330\end{array}$ \\
\hline 18 & $\begin{array}{r}0 \\
45 \\
75 \\
105\end{array}$ & $\begin{array}{l}-\quad 45 \\
-\quad 75 \\
-\quad 105 \\
-120\end{array}$ & $\begin{array}{l}0,0002 \\
0,0002 \\
0,0003 \\
0,0004\end{array}$ & $\begin{array}{l}0,0090 \\
0,0060 \\
0,0090 \\
0,0060\end{array}$ & $\begin{array}{l}0,0090 \\
0,0150 \\
0,0240 \\
0,0300\end{array}$ \\
\hline 20 & $\begin{array}{r}0 \\
45 \\
75 \\
105\end{array}$ & $\begin{array}{r}-\quad 45 \\
-\quad 75 \\
-\quad 105 \\
-\quad 120\end{array}$ & $\begin{array}{l}0,0002 \\
0,0002 \\
0,0003 \\
0,0004\end{array}$ & $\begin{array}{l}0,0090 \\
0,0060 \\
0,0090 \\
0,0060\end{array}$ & $\begin{array}{l}0,0090 \\
0,0150 \\
0,0240 \\
0,0300\end{array}$ \\
\hline 25 & $\begin{array}{r}0 \\
45 \\
75 \\
105\end{array}$ & $\begin{array}{l}-\quad 45 \\
-\quad 75 \\
-\quad 105 \\
-\quad 120\end{array}$ & $\begin{array}{l}0,0002 \\
0,0002 \\
0,0003 \\
0,0004\end{array}$ & $\begin{array}{l}0,0090 \\
0,0060 \\
0,0090 \\
0,0060\end{array}$ & $\begin{array}{l}0,0090 \\
0,0150 \\
0,0240 \\
0,0300\end{array}$ \\
\hline 30 & $\begin{array}{r}0 \\
45 \\
75 \\
105\end{array}$ & $\begin{array}{r}-\quad 45 \\
-\quad 75 \\
-\quad 105 \\
-\quad 120\end{array}$ & $\begin{array}{l}0,0002 \\
0,0002 \\
0,0003 \\
0,0004\end{array}$ & $\begin{array}{l}0,0090 \\
0,0060 \\
0,0090 \\
0,0060\end{array}$ & $\begin{array}{l}0,0090 \\
0,0150 \\
0,0240 \\
0,0300\end{array}$ \\
\hline
\end{tabular}


Tabela n? 04 (cont.)

\begin{tabular}{|c|c|c|c|c|c|}
\hline $\begin{array}{c}t \\
(d i a)\end{array}$ & & $\begin{array}{c}\mathrm{Z} \\
(\mathrm{cm})\end{array}$ & $\frac{-\frac{\partial \theta}{\partial t}}{\left(\mathrm{~cm}^{3} \cdot \mathrm{cm}^{-3} \cdot \mathrm{dia}^{-1}\right)}$ & $\begin{array}{r}-d z\left(-\frac{\partial \theta}{\partial t}\right) \\
c m \cdot d i a^{-1}\end{array}$ & $\begin{array}{r}-\sum d z(\partial \theta / \partial t) \\
\left(\mathrm{cm} \cdot \mathrm{dia}^{-1}\right)\end{array}$ \\
\hline 35 & $\begin{array}{r}0 \\
45 \\
75 \\
105\end{array}$ & $\begin{array}{l}-\quad 45 \\
-\quad 75 \\
-\quad 105 \\
-\quad 120\end{array}$ & $\begin{array}{l}0,0002 \\
0,0002 \\
0,0003 \\
0,0004\end{array}$ & $\begin{array}{l}0,0090 \\
0,0060 \\
0,0090 \\
0,0060\end{array}$ & $\begin{array}{l}0,0090 \\
0,0150 \\
0,0240 \\
0,0300\end{array}$ \\
\hline 40 & $\begin{array}{r}0 \\
45 \\
75 \\
105\end{array}$ & $\begin{array}{l}-\quad 45 \\
-\quad 75 \\
-\quad 105 \\
-\quad 120\end{array}$ & $\begin{array}{l}0,0002 \\
0,0002 \\
0,0003 \\
0,0004\end{array}$ & $\begin{array}{l}0,0090 \\
0,0060 \\
0,0090 \\
0,0060\end{array}$ & $\begin{array}{l}0,0090 \\
0,0150 \\
0,0240 \\
0,0300\end{array}$ \\
\hline
\end{tabular}


tempo da figura 6 constata-se que a redistribuição da ăgua do solo difere sensivelmente entre camadas. Para as duas primeiras camadas a umidade $\theta$ apresenta variações muito pequenas após um período relativamente cur to ( 6 e 8 dias para la. e 2a. camada, respectivamente) e para as duas últimas apōs um período bem maior (16 dias para ambas) e quanto ao teor de umidade correspondente a estes períodos de tempo tem-se: 0,$348 ; 0,319$; 0,296 e $0,335 \mathrm{~cm}^{3} \cdot \mathrm{cm}^{-3}$, para la, 2a., 3a. e 4a. camada, respectivamente. Isto vem mostrar que o parâmetro capacidade de campo não é estático e que sua determinação obrigatoriamente deverã ser feita no campo, pois o seu valor està estritamente relacionado com a heterogeneidade do perfil, profundidade do solo considerado, alēm de outras características como descreve REICHARDT' (1975).

Na Tabela 5 encontram-se os valores da condutividade hidráulica em função do conteūdo de àgua do solo obtidos pelo procedimento sugerido por HILLEL et alii (1972). A coluna 2 desta Tabela apresenta o teor de umidade médio $(\bar{\theta})$ que foi obtido determinando-se a média dos valo res de umidade extraidos das curvas da Figura 5 para os períodos de tempo considerados. A coluna 3 mostra a variação do gradiente de potencial total da àgua do solo calculado atravès da expressão:

$$
\frac{\Delta \psi}{\Delta z}=\frac{\bar{\psi}_{105}-\bar{\psi}_{135}}{\Delta z}
$$

onde:

$$
\begin{aligned}
\Delta \psi / \Delta z= & \text { gradiente de potencial total da agua do solo a } 120 \\
& \mathrm{~cm} \text { de profundidade. } \\
\psi_{105=} & \begin{array}{l}
\text { potencial total da água do solo a } 105 \mathrm{~cm} \text { de profun } \\
\text { didade. }
\end{array}
\end{aligned}
$$


Tabela n? 05

Condutividade Hidrāulica em função do conteūdo de água do solo médio (Méto do de HILLEL et alii, 1972).

\begin{tabular}{ccccc}
\hline $\begin{array}{c}t \\
\text { (dia) }\end{array}$ & $\bar{\theta}$ & $-\frac{\Delta \Psi}{\Delta Z}$ & $-\sum \mathrm{dz}\left(\frac{\partial \theta}{\partial \mathrm{t}}\right)=-q$ & $\bar{K}(\theta)$ \\
$\left(\mathrm{cm}^{3} \cdot \mathrm{cm}^{-3}\right)$ & $\left(\mathrm{cm}^{-3} \mathrm{~cm}^{-1}\right)$ & $\left.\mathrm{dia}^{-1}\right)$ & $\left({\left.\mathrm{cm} . \mathrm{dia}^{-1}\right)}^{-1}\right.$ \\
\hline 1 & 0,3720 & 1,8767 & 0,7920 & 0,4220 \\
2 & 0,3645 & 1,9633 & 0,4965 & 0,2529 \\
3 & 0,3591 & 2,0167 & 0,3390 & 0,1681 \\
4 & 0,3548 & 2,1033 & 0,2475 & 0,1177 \\
5 & 0,3510 & 2,1400 & 0,1680 & 0,0785 \\
6 & 0,3478 & 2,1800 & 0,1335 & 0,0612 \\
8 & 0,3426 & 2,2567 & 0,0825 & 0,0366 \\
10 & 0,3395 & 2,3033 & 0,0555 & 0,0241 \\
12 & 0,3376 & 2,3667 & 0,0450 & 0,0190 \\
14 & 0,3363 & 2,4133 & 0,0390 & 0,0162 \\
16 & 0,3353 & 2,4533 & 0,0330 & 0,0135 \\
18 & 0,3345 & 2,4933 & 0,0300 & 0,0120 \\
20 & 0,3338 & 2,5233 & 0,0300 & 0,0119 \\
25 & 0,3320 & 2,5933 & 0,0300 & 0,0116 \\
30 & 0,3303 & 2,6500 & 0,0300 & 0,0113 \\
35 & 0,3286 & 2,6967 & 0,0300 & 0,0111 \\
40 & 0,3268 & 2,7700 & 0,0300 & 0,0108 \\
& & & & \\
\hline
\end{tabular}


$\psi_{135}=$ Potencial total da ăgua do solo a $135 \mathrm{~cm}$ de profundidade.

$z=$ Coordenada vertical de posição.

0s valores de $\bar{\psi}_{105}$ e $\bar{\psi}_{135}$ encontram-se na Figura 7 e foram obtidos de curvas de potencial total versus tempo dos dezesseis tensiônetros ( 8 a $105 \mathrm{~cm}$ e 8 a $135 \mathrm{~cm}$ de profundidade) dos vinte instalados na parcela. Observe-se a eliminação de quatro tensiômetros devido ao aparecimento de defeitos como pode ser observado na Tabela $3\left(\begin{array}{lll}T_{4} & \text { e } & T_{9}\end{array}\right)$.

Com os dados da Tabela 5 construiu-se a Figura 12 que ex pressa o valor médio da condutividade hidráulica em função do conteūdo mé dio da água do solo. Como os pontos plotados de LK( $\theta)$ versus $\theta$ distribuiram-se segundo uma linha reta, fez-se um estudo de regressão linear obtendo-se a equação $K(\theta)=\exp 36,78(2,643 \bar{\theta}-1)$ com o valor $r=0,95$. Deve-se observar que na Figura 12 estão tambēm incluidas as curvas de condutividade hidráulica correspondentes aos locais onde foram instalados os quatro tubos de acesso $\left(N_{1}, N_{2}, N_{3}\right.$ e $\left.N_{4}\right)$. Para este fim seguiu-se um procedimento semelhante ao empregado para a curva média de $k(\theta)$, observando-se que o gradiente de potencial foi determinado pelo número de tensiômetros existentes nas proximidades de cada tubo, como mostram as Figuras $1,8,9,10$ e 11 .

Comparando-se os valores da condutividade hidräulica das cinco curvas apresentadas na Figura 12 constata-se a fidelidade do empre go do método, pois a aplicação de anālise de regressão linear, onde consi derou-se tambēm a condutividade hidrāulica saturada, apresentou valores 


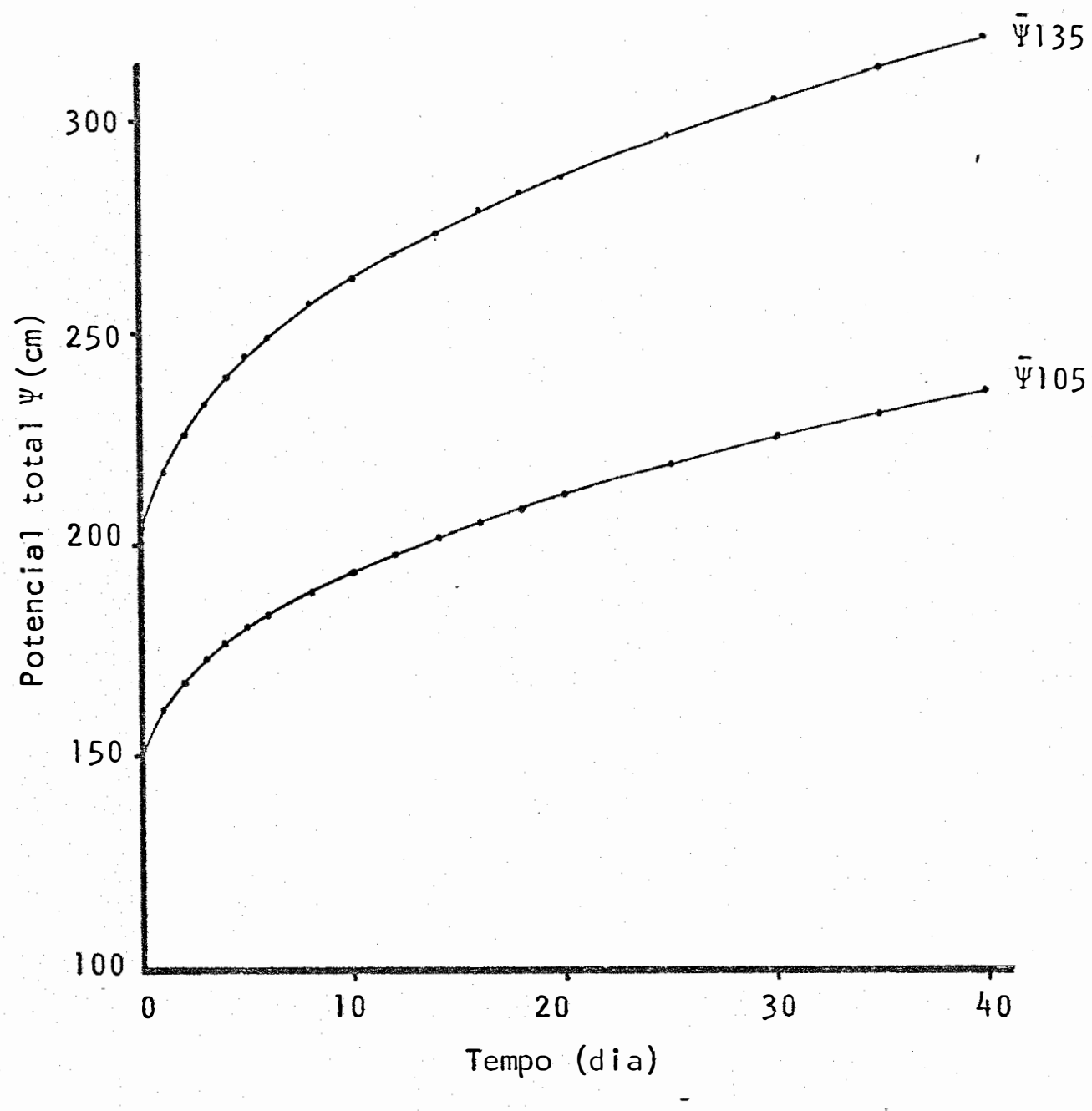

Figura 7 - Variação média do potencial total da água do solo na parcela durante o período de redistribuição nas profundidades 105 e $135 \mathrm{~cm}$. 
.38 .

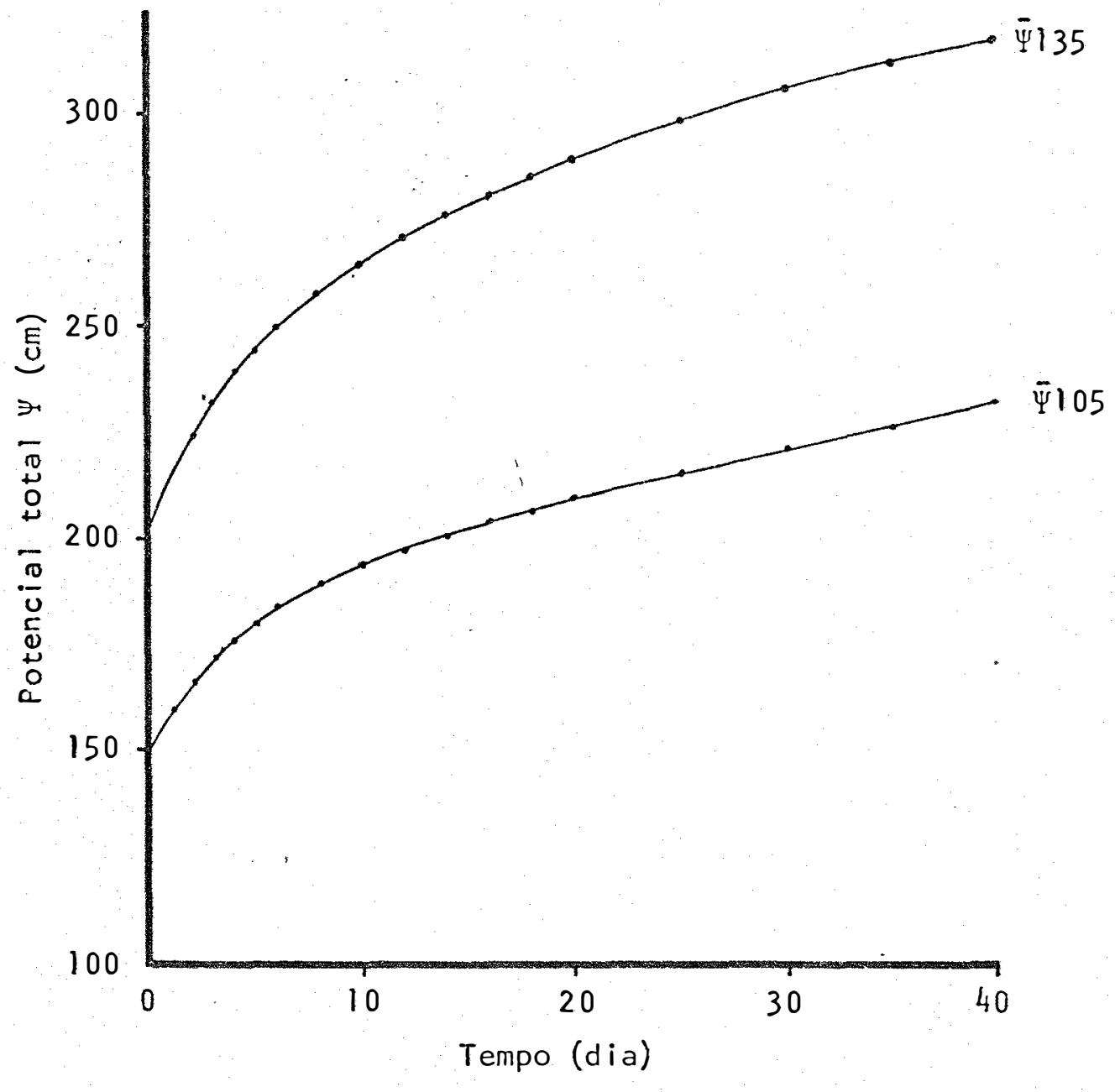

Figura 8 - Variação média do potencial total da água do solo no tubo de acesso $N_{1}$ durante o período de redis tribuição nas profundidades de 105 e $135 \mathrm{~cm}$. 


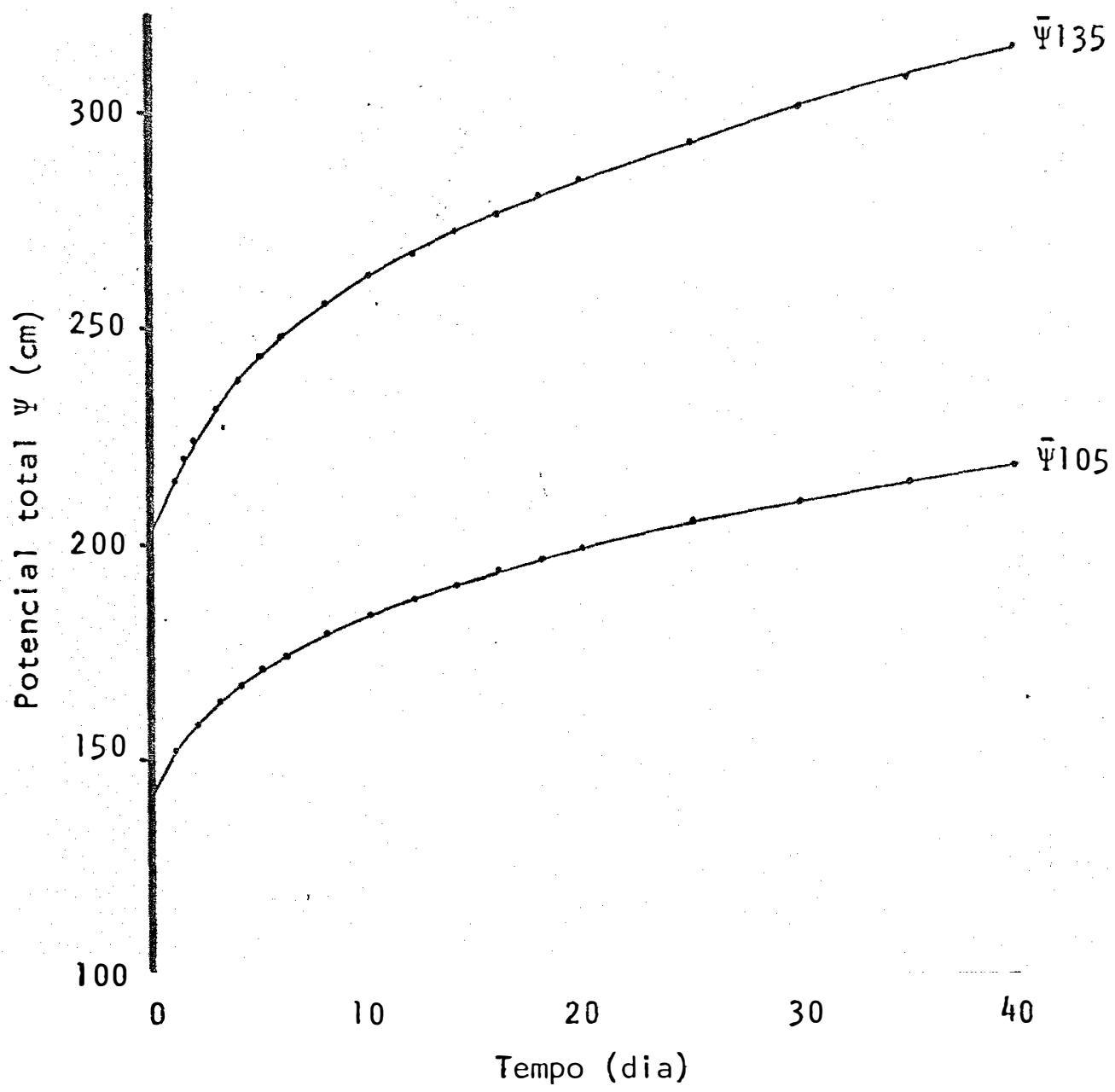

Figura 9 - Variação média do potencial total da ägua do solo no tubo de acesso $N_{2}$ durante o período de redistribuição nas profundidades de 105 e $135 \mathrm{~cm}$. 


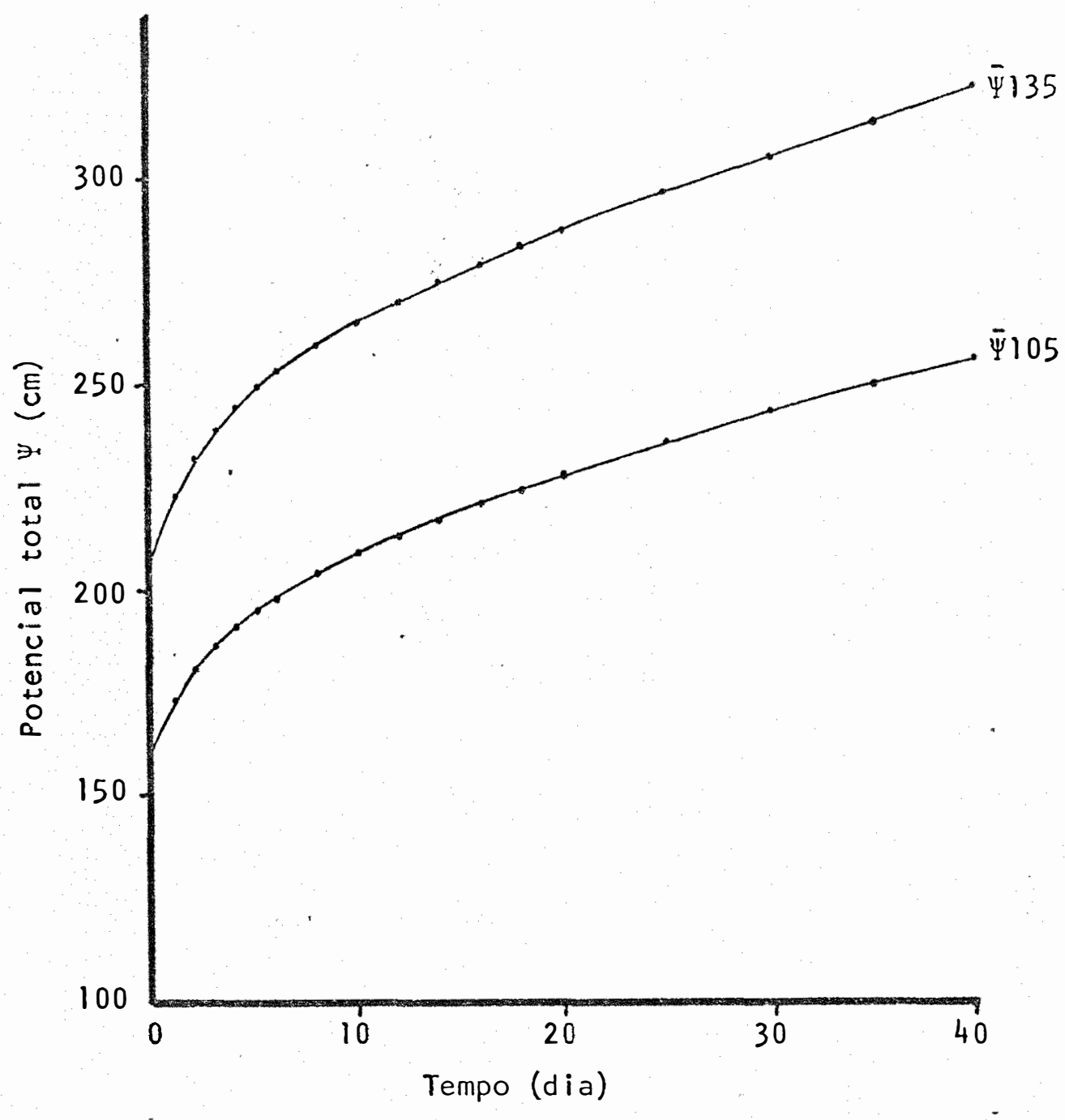

Figura 10 - Variação média do potencial total da āgua do solo do tubo de acesso $\mathrm{N}_{3}$ durante o período de redistribuição nas profundidades de 105 e $135 \mathrm{~cm}$. 


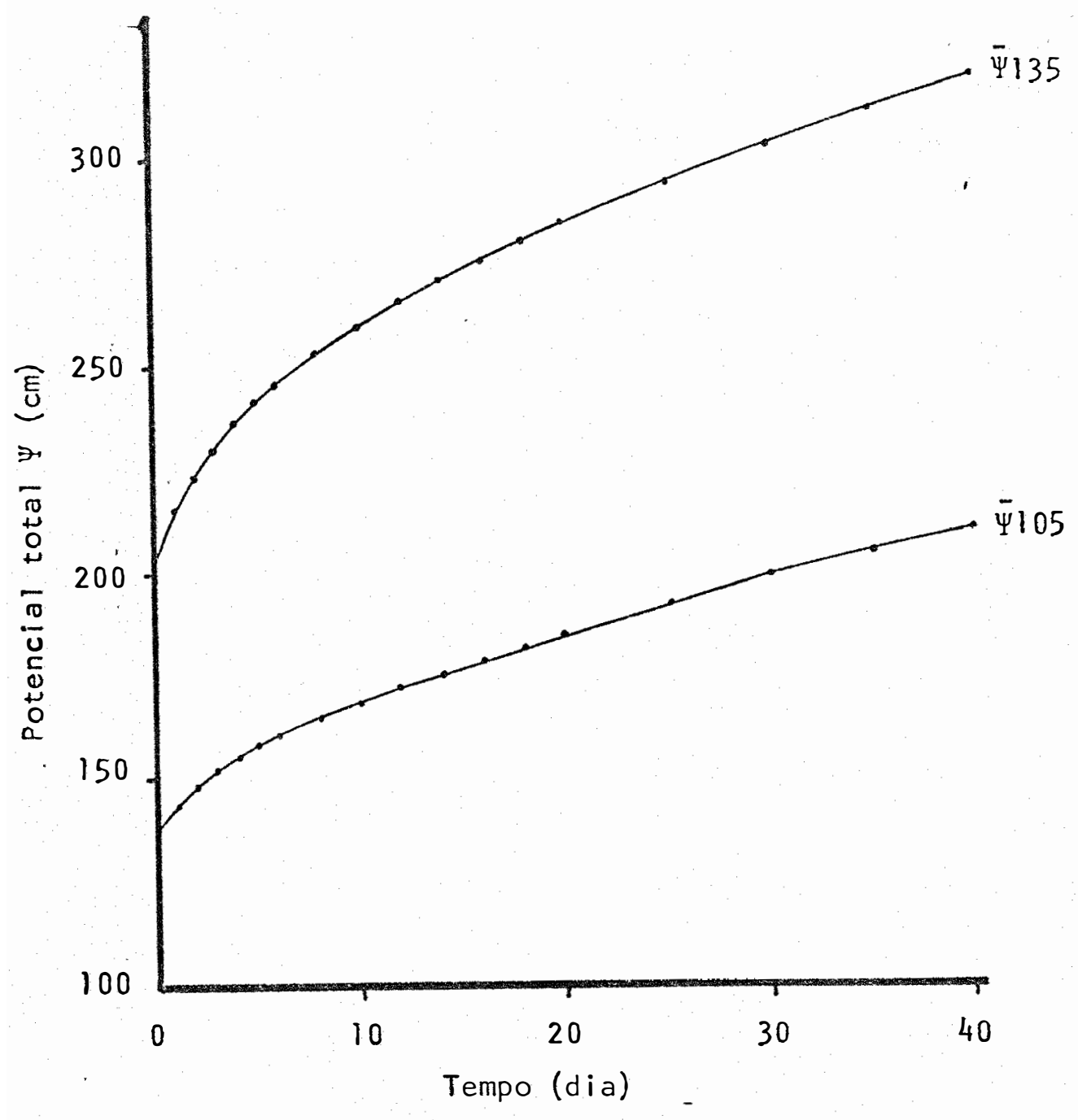

Figura 11 - Variação média do potencial total da água do solo no tubo de acesso $\mathrm{N}_{4}$ durante o período de redistri buição nas profundidades de 105 e $135 \mathrm{~cm}$. 
.42.

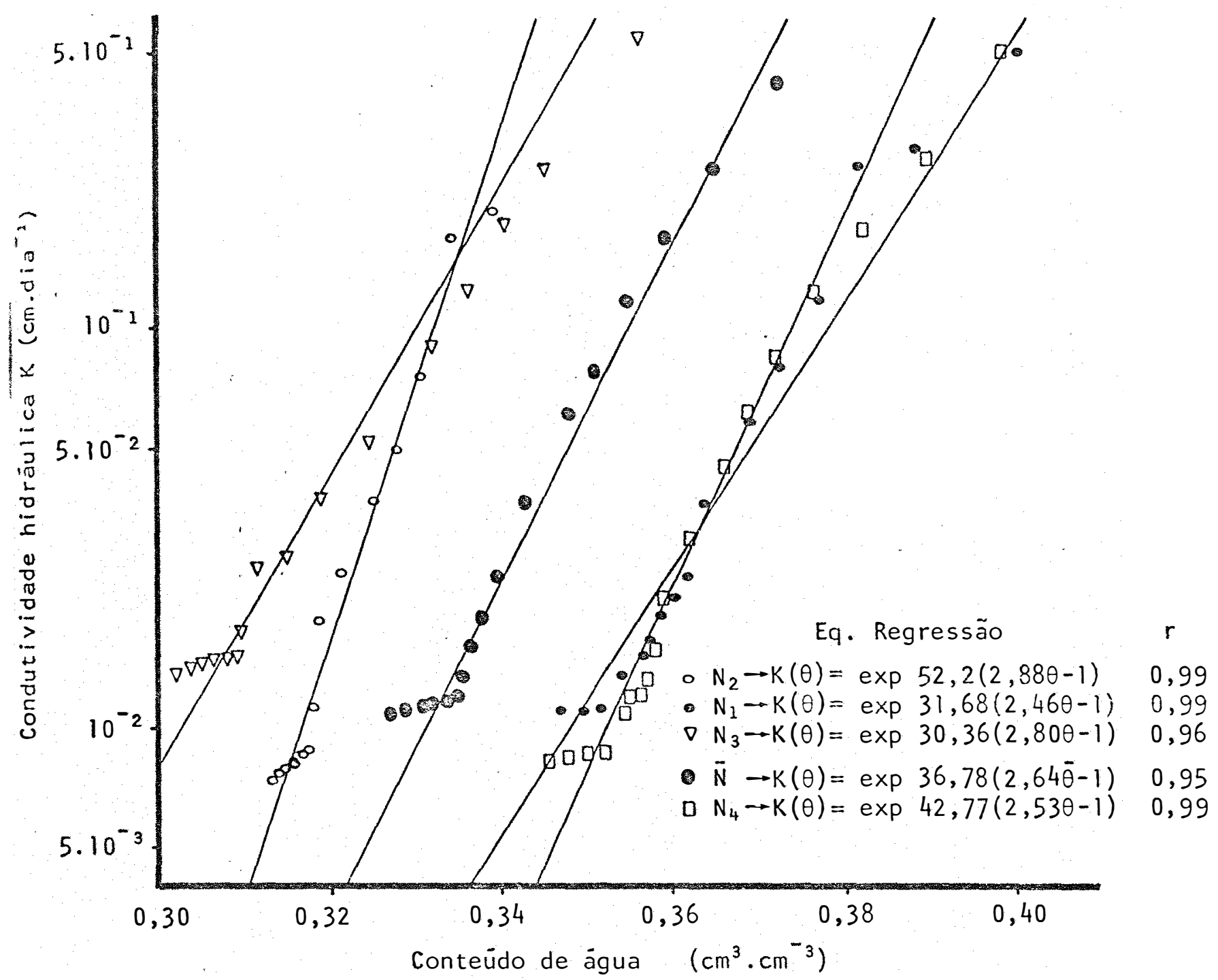

Figura 12 - Gräfico da condutividade hidräulica (Método de HILLEL et alii, 1972) em função do conteüdo de ägua do solo para os quatro locais escolihidos ao acaso na parcela experimental com as respectivas equações de regressão e a curva média. 
do coeficiente de correlação para as cinco determinaçōes superiores a 0,95 . REICHARDT e LIBARDI (1974) e REICHARDT et alii (1976) que trabalhäram nes ta mesma área, encontraram valores de condutividade hidräulica bem compatíveis com os apresentados na Figura 12 .

Analisando a Figura 12 observa-se que para baixos valores da umidade $\theta\left(<0,322 \mathrm{~cm}^{3} \cdot \mathrm{cm}^{-3}\right)$ deixa de existir a linearidade dos pontos de $K$ versus $\theta$ (o que normalmente ocorre para valores mais elevados). Tal fato é justificado pela dificuldade de se traçar corretamente trechos das curvas de $\theta$ versus tempo, quando a variação da umidade $\theta$ for pequena, devido ao erro de precisão da sonda de neutrons e consequentemente conseguir valores mais precisos de tangentes a estas curvas para a obtenção da densidade de fluxo. Nos trabalhos desenvolvidos por NIELSEN et alii (1973), REICHARDT e LIBARDI (1974) e outros observa-se também esta limita ção do método de HILLEL et alii. (1972).

\subsubsection{Método de HILLEL Modificado (I)}

As curvas médias das figuras 13 e 14 foram obtidas a partir dos dados da Tabela 6. A Figura 13 que representa a variação do armą zenamento da àgua do solo com o tempo, aprésenta além da curva média, as curvas individuais dos locais onde foram instalados ao acaso os quatro tú bos de acesso $\left(N_{1}, N_{2}, N_{3}\right.$ e $\left.N_{4}\right)$. Os valores do armazenamento contidos na coluna 2 da Tabela 6 foram determinados pelo processo de aproximação, considerando-se a umidade $\theta$ constante ao longo de uma camada num determinado tempo e calculando-se o armazenamento $\mathrm{W}$ pelo somatốrio do produto da umi- 
Tabela n? 06

.44

Condutividade Hidráulica em função dos valores médios do armazenamento da água do solo na profundidade de $120 \mathrm{~cm}$ para diversos tempos. Método de HILLEL modificado ( 1 ).

\begin{tabular}{|c|c|c|c|c|}
\hline $\begin{array}{l}\text { Tempo } \\
\text { (dia) }\end{array}$ & $\begin{array}{l}W \\
(\mathrm{~cm})\end{array}$ & $-\frac{\partial W}{\partial t}$ & $-\frac{\Delta \Psi}{\Delta 7}$ & $\begin{array}{c}K(\theta) \\
\left(\mathrm{cm} \cdot \mathrm{dia}^{-1}\right)\end{array}$ \\
\hline 1 & 41,3130 & 0,8353 & 1,8767 & 0,4451 \\
\hline 2 & 40,6770 & 0,5194 & 1,9633 & 0,2646 \\
\hline 3 & 40,2495 & 0,3406 & 2,0167 & 0,1689 \\
\hline 4 & 39,9720 & 0,2576 & 2,1033 & 0,1225 \\
\hline 5 & 39,7680 & 0,1717 & 2,1400 & 0,0802 \\
\hline 6 & 39,6240 & 0,1286 & 2,1800 & 0,0590 \\
\hline 8 & 39,4290 & 0,0811 & 2,2567 & 0,0359 \\
\hline 10 & 39,2955 & 0,0605 & 2,3033 & 0,0263 \\
\hline 12 & 39,1905 & 0,0485 & 2,3667 & 0,0205 \\
\hline 14 & 39,1080 & 0,0382 & 2,4133 & 0,0158 \\
\hline 16 & 39,0285 & 0,0365 & 2,4533 & 0,0149 \\
\hline 18 & 38,9625 & 0,0365 & 2,4933 & 0,0146 \\
\hline 20 & 38,9010 & 0,0307 & 2,5233 & 0,0122 \\
\hline 25 & 38,7450 & 0,0304 & 2,5933 & 0,0117 \\
\hline 30 & 38,5905 & 0,0288 & 2,6500 & 0,0109 \\
\hline 35 & 38,4465 & 0,0288 & $2,69.67$ & 0,0107 \\
\hline 40 & 38,3055 & 0,0288 & 2,7700 & 0,0104 \\
\hline
\end{tabular}




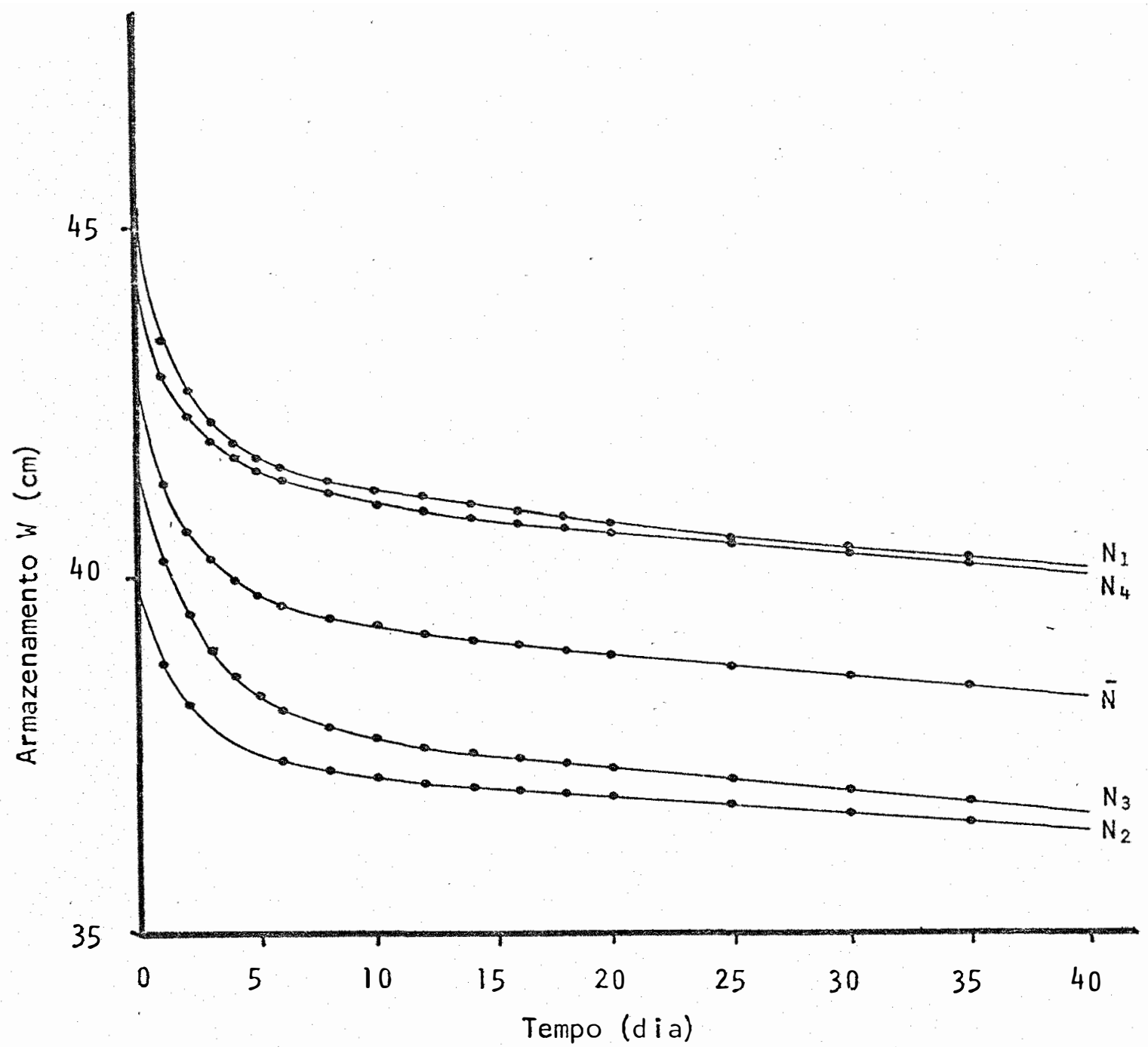

Figura 13 - Variação do armazenamento da água do solo durante o período de redistribuição na profundidade de $0-120 \mathrm{~cm}$. 
.46 .

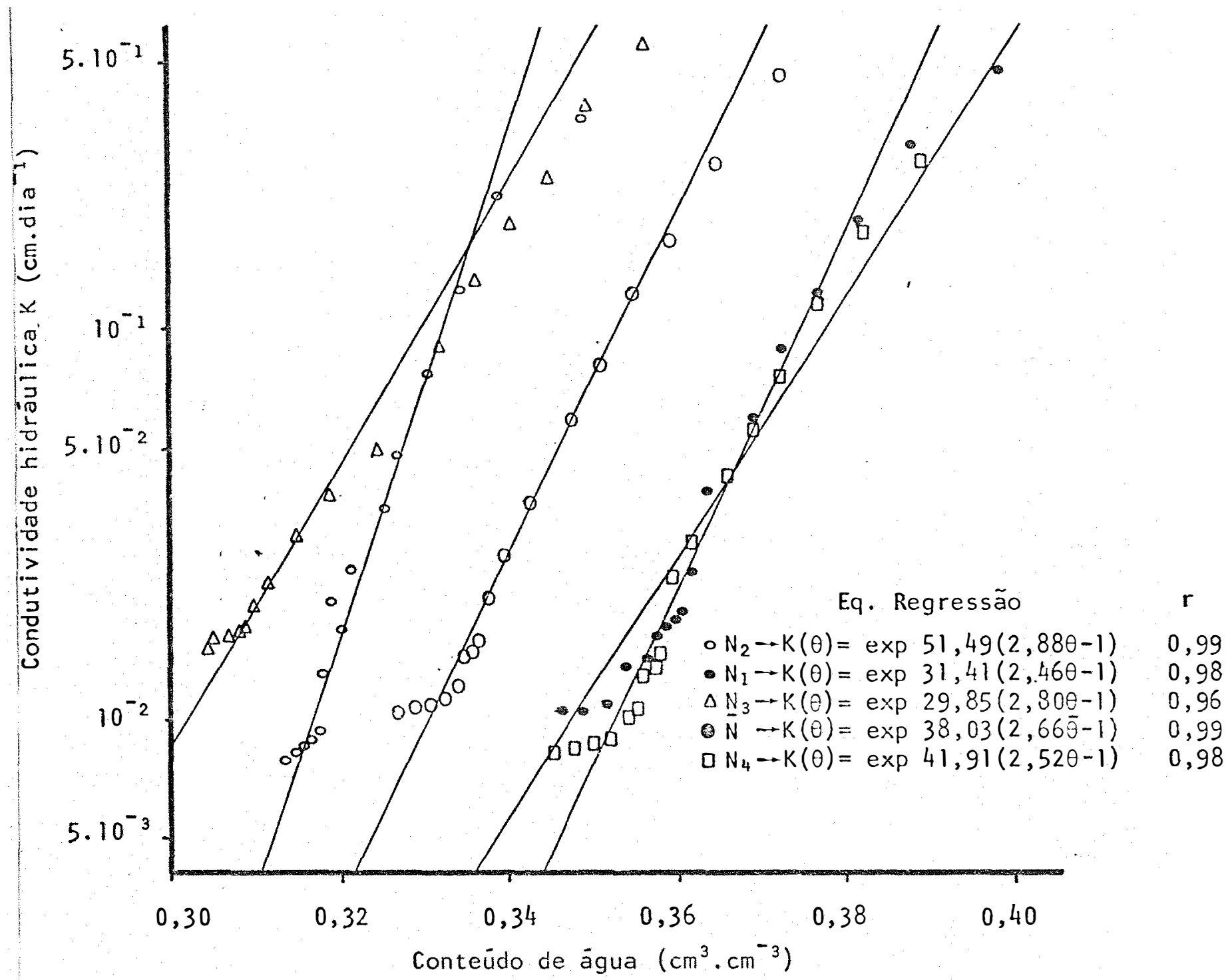

Figura 14 - Gräfico da condutividade hidrāulica [Método de HILlel Modificado (1)] em função do conteúdo de água do solo para os quatro lo cais escolhidos ao acaso na parcela experimental com as respecti vas equações de regressão e a curva média. 
dade $\theta$ em cada camada e sua expessura. A Figura 14 mostra as curvas da condutividade hidrāulica em função do conteúdo de água do solo tanto para o valor médio como para os quatro pontos individuais.

Analisando as equações de regressão linear das curvas da Figura 14 denota-se uma fidelidade no procedimento do método, pois o menor valor encontrado para o coeficiente de correlação foi superior a 0,96 . Comparando-se as Figuras 12 e 14 verifica-se uma similaridade entre as curvas correspondentes, como pode-se demonstrar através das equações de $K(\bar{\theta})$ dos dois métodos que exprimem resultados praticamente iguais da condutividade hidrāulica para um mesmo valor do conteúdo de água do so 1o, pois, para $\bar{\theta}=0,340 \mathrm{~cm}^{3} \cdot \mathrm{cm}^{-3}$ o método de HILLEL et alii (1972) forne ce um valor de $K(\bar{\theta})=2 \cdot 4 \cdot 10^{-2} \mathrm{~cm} \cdot d^{-1}$ e para o método modificado (1) $K(\bar{\theta})=2 \cdot 5 \cdot 10^{-2} \mathrm{~cm}^{-d i a^{-1}}$.

Deve-se salientar que neste segundo método também deixa de existir a linearidade dos pontos de $K$ versus $\theta$ para valores do conteúdo de água inferior a $0,322 \mathrm{~cm}^{3} \cdot \mathrm{cm}^{-3}$ como ocorreu no método de HILLEL et alii (1972) .

\subsubsection{Método de HILLEL Modificado (II)}

Com os dados das colunas 1 e 2 da Tabela 7 construiu-se a Figura 15 que expressa variação do armazenamento da àgua do solo em função do tempo (em escala semi-logarítmica). As equações dos segmentos de reta desta figura, quando derivadas em relação ao tempo, exprimem analiti 
Condutividade Hidráulica em função dos valores médios do armazenamentọ da água do solo na profundidade de $120 \mathrm{~cm}$ para diversos tempos. A densidade de fluxo é calculada analitícamente pela expressão $q=\frac{b}{t}$. Método de HILLEL Modificado (11) $\cdot b=0,7635$

\begin{tabular}{ccccc}
\hline $\begin{array}{c}\text { Tempo } \\
(\mathrm{dia})\end{array}$ & $\begin{array}{c}W \\
(\mathrm{~cm})\end{array}$ & $\begin{array}{c}-q \\
\left(\mathrm{~cm} . \mathrm{dia}^{-1}\right)\end{array}$ & $\begin{array}{c}-\frac{\Delta \Psi}{\Delta Z} \\
\left(\mathrm{~cm} . \mathrm{cm}^{-1}\right)\end{array}$ & $\begin{array}{c}K(\theta) \\
\left(\mathrm{cm} . \mathrm{dia}^{-1}\right)\end{array}$ \\
\hline 1 & 41,3130 & 0,7635 & 1,8767 & 0,4068 \\
2 & 40,6770 & 0,3818 & 1,9633 & 0,1945 \\
3 & 40,2495 & 0,2545 & 2,0167 & 0,1262 \\
4 & 39,9720 & 0,1909 & 2,1033 & 0,0908 \\
5 & 39,7680 & 0,1527 & 2,1400 & 0,0714 \\
6 & 39,6240 & 0,1273 & 2,1800 & 0,0584 \\
8 & 39,4290 & 0,0954 & 2,2567 & 0,0423 \\
10 & 39,2955 & 0,0764 & 2,3033 & 0,0232 \\
12 & 39,1905 & 0,0636 & 2,3667 & 0,0269 \\
14 & 39,1080 & 0,0545 & 2,4133 & 0,0226 \\
16 & 39,0285 & 0,0477 & 2,4533 & 0,0194 \\
18 & 38,9125 & 0,0424 & 2,4933 & 0,0170 \\
20 & 38,9010 & 0,0382 & 2,5233 & 0,0151 \\
25 & 38,7450 & 0,0305 & 2,5933 & 0,0118 \\
30 & 38,5905 & 0,0255 & 2,6500 & 0,0096 \\
35 & 38,4465 & 0,0218 & 2,6767 & 0,0081 \\
40 & 38,3055 & 0,0191 & 2,7700 & 0,0069 \\
& & & & \\
\hline
\end{tabular}




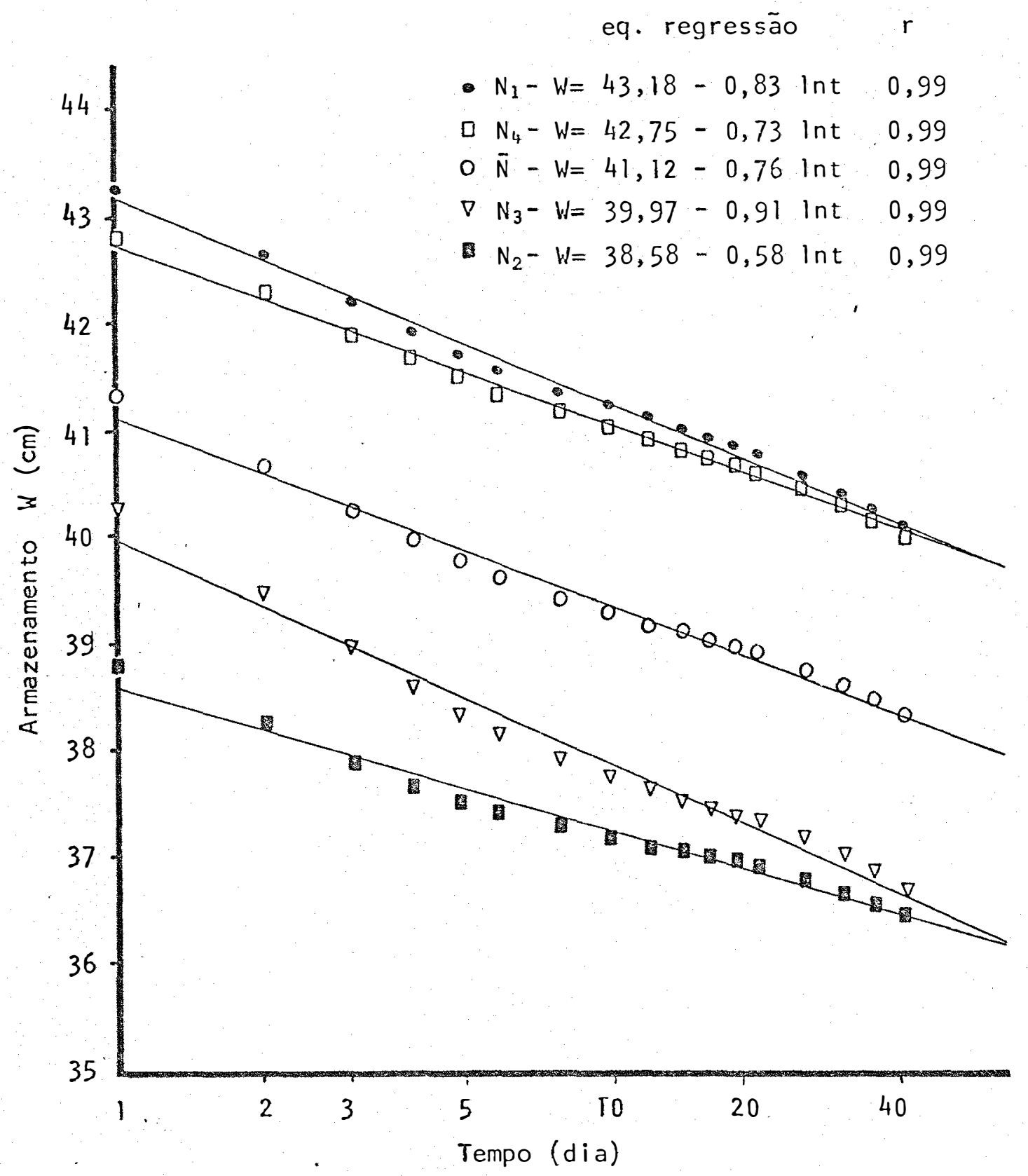

Figura 15 - Variação do armazenamento da àgua do solo durante o período de redistribuição para a profundidade de $0-120 \mathrm{~cm}$. 
camente os valores da densidade de fluxo como mostra a coluna 3 da Tabe1a 7. Assim, determinou-se a condutividade hidráulica e construiu-se a Figura 16 que representa este parâmetro em função do conteüdo de água do solo.

0 estudo da anālise de regressão linear para à curva média e para os locais dos tubos de acesso da condutividade hidrâulica versus umidade $\theta$ mostrou uma grande coerência nos resultados obtidos, pois o valor do coeficiente de correlação $r$ foi sempre superior a 0,94 .

A grande vantagem apresentada por este método è mostrada na Figura 16, onde se verifica a linearidade dos pontos $K$ versus $\theta$ para qualquer valor de umidade. Isto decorre da determinação da densidade de fluxo por procedimento analítico, em detrimento da confecção de curvas e traçado de tangentes como exige os outros dois métodos estudados que normalmente conduzem a erros e, especialmente quando a variação da umidade $\theta$ ou do armazenamento for muito pequena, pois impede maiores detalhes de precisão na confeç̧ão das curvas e traçado de tangente às mesmas.

Um estudo comparativo dos três métodos feito através da Fi gura 17, onde se representou as curvas mêdias da condutividade hidráulica em função da umidade $\theta$, mostra a validade dos mesmos, pois, verifica-se uma grànde uniformidade na distribuição dos pontos e para um mesmo conteúdo de ăgua o valor da condutividade hidráulica não difere em ordem da grandeza para ós três métodos. 
.51

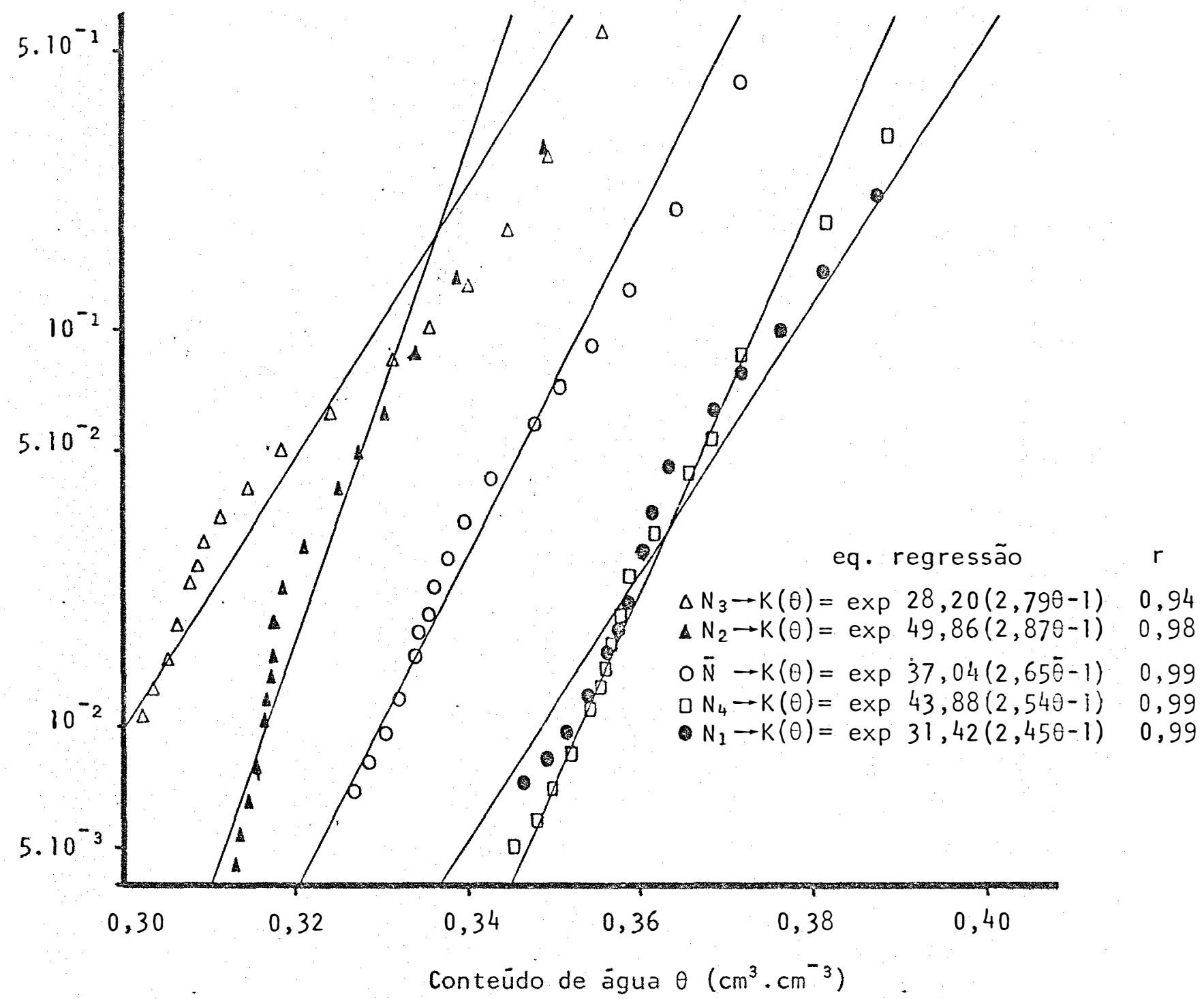

Figura 16 - Gräfico da condutividade hidräulica [Método de H!LLEL Modificado (11)] em função do conteúdo de água do solo para os quatro locais escolhidos ao acaso na parcela experimental com as respectivas curvas de regressão e a curva média. 


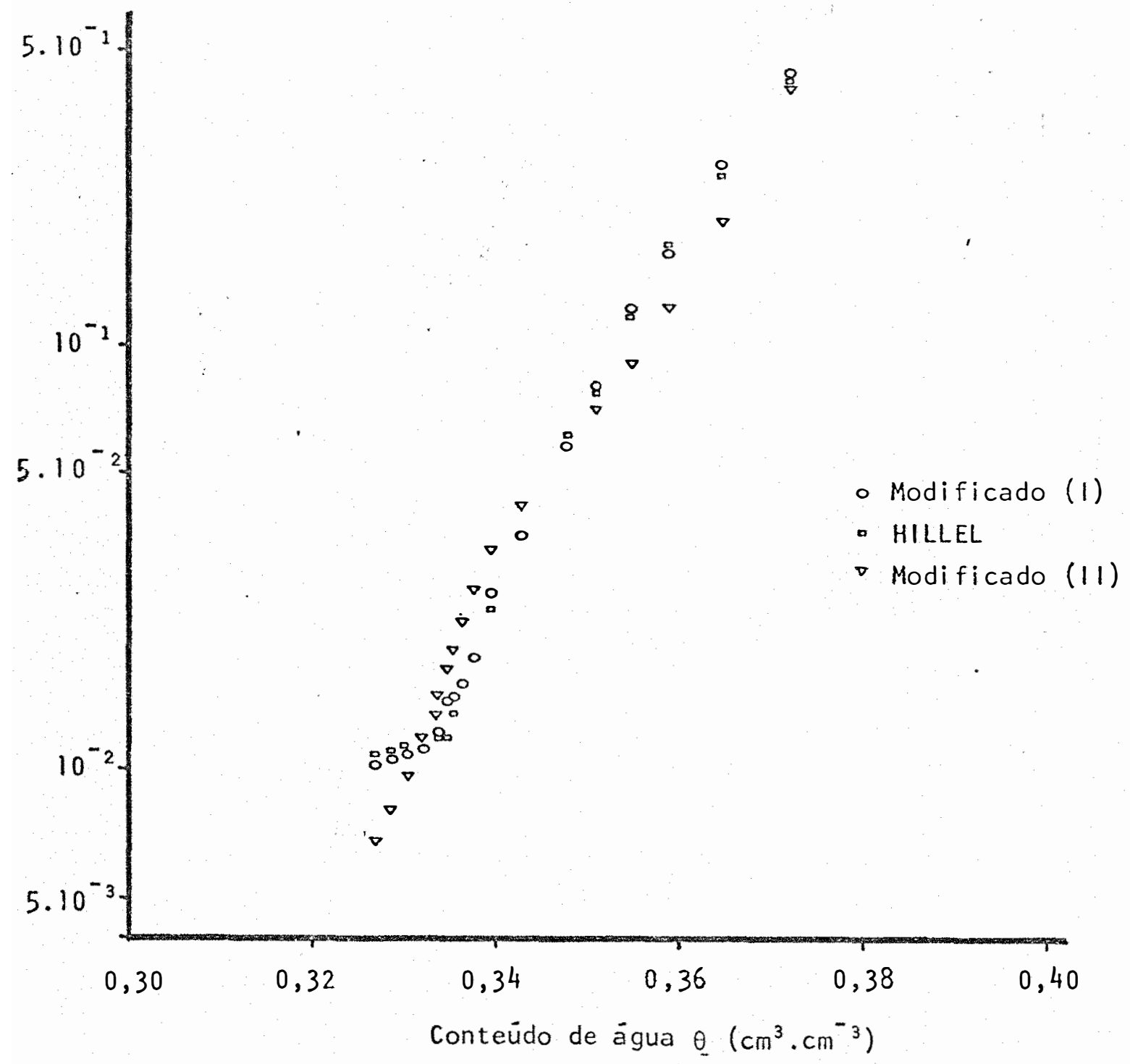

Figura 17 - Valores médios da condutividade hidräulica em função do conteúdo médio da água do solo para os 3 métodos estudados. 


\subsubsection{Propagação de erros}

Para o estudo de propagação de erros escolheu-se ao acaso o método de HILLEL Modificado (1) com o intuito de facilitar a discussão, pois, como já foi discutido anteriormente, os três métodos apresentaram resultados coerentes, não havendo, portanto, necessidade de se desenvolver a metodologia de erros para todos os métodos estudados.

A Figura 14 mostra as relações de $K(\theta)$ para quatro pontos individuais dentro da parcela, correspondentes aos tubos de acesso instalados ao acaso $\left(N_{2}, N_{2}, N_{3}\right.$ e $\left.N_{4}\right)$ e tensiômetros situados pröximo aos mesmos. Numa tentativa de mostrar-se a magnitude da variabilidade espacial dentro da parcela, determinou-se para um conteüdo de ägua especifico, $\theta=0,344 \mathrm{~cm}^{3} \cdot \mathrm{cm}^{-3}$, os valores de $K(\theta)$ para as curvas $N_{3}, \bar{N}$ e $N_{4}$ e obteve $0,3429,0,0402$ e $0,0036 \mathrm{~cm} \mathrm{dia}^{-1}$ respectivamente, o que representa aproxi madamente um aumento de 10 vezes do valor de $k(\theta)$ para cada curva, o que está de acordo com os resultados obtidos por REICHARDT et alii(1976). Do exposto, pode-se afirmar que a utilização destas curvas exige um grande cuidado, pois, para utilização de uma das curvas de pontos individuais a umidade $\theta$ deverá ser obtida do ponto correspondente à curva e no caso da curva média, os dadosde umidade $\theta$ deverão ser representativos da média da parcela.

Dispondo-se da curva $K(\theta)$ versus $\theta$ do tubo de acesso $\mathrm{N}_{2}$ e pretendendo-se obter valores da condutividade hidräulica a partir de dados de umidade $\theta$, pröximo à saturação, medidos no tubo de acesso $N_{1}$, ver $\underline{\mathbf{i}}$ fica-se que tal procedimento do ponto de vista físico é impossivel. Is- 
to porque para as condições de campo, a umidade de saturação de $N_{1}$ e $N_{2}$ na profundidade de $120 \mathrm{~cm}$ corresponde a 0,443 e $0,359 \mathrm{~cm}^{3} \cdot \mathrm{cm}^{-3}$, respectivamente, o que impede a extrapolação para a obtenção de valores de $K(\theta)$ atravēs da curva $\mathrm{N}_{2}$ quando o valor de $\theta$ for superior a $0,359 \mathrm{~cm}^{3} \cdot \mathrm{cm}^{-3}$. Es te aspecto também foi estudado por NIELSEN et ali i (1973) entre parcelas e constataram problemas similares.

o grande problema da variabilidade espacial da condutivida de hidrāulica deve-se à variação exponencial deste parâmetro com o conteü do de água do solo, como será discutido posteriormente. Numa tentativa de atenuar este problema procurou-se normalizar as curvas da condutividade hidrāulica em função da umidade de saturação como sugere NIELSEN et ali i (1973). Assim, construiu-se a Figura 18 que representa K em função da diferença entre umidade de saturação $\left(\theta_{0}\right)$ e a umidade $\theta$ num determinado tempo. Embora a taxa de infiltração seja altamente correlacionada com a percentagem de saturação e não com o conteúdo de água do solo, e as curvas de $K(\theta)$ na Figura 18 apresente menor afastamento entre si na abcis sa, verifica-se, no entanto, uma preservação na precisão destas curvas, pois os valores de $\mathrm{K}$ para um determinado valor de umidade $\theta$ são idênticos nas Figuras 14 e 18 , donde se conclui que tal procedimento normaliza as curvas, mas não resolve o problema de variabilidade espacial.

Procurando-se estabelecer um critërio para garantir uma margem de segurança quando da utilização da curva média da condutividade hidräulica, fez-se um estudo de erros das variāveis que são envolvidas no cálculo de $K(\theta)$ como mostra a Tabela 8 . Os dados apresentados nesta tabela foram obtidos manipulando-se os valores normalizados dos pontos correspondentes aos quatro tubos de acesso e aplicando-se as expressões de 


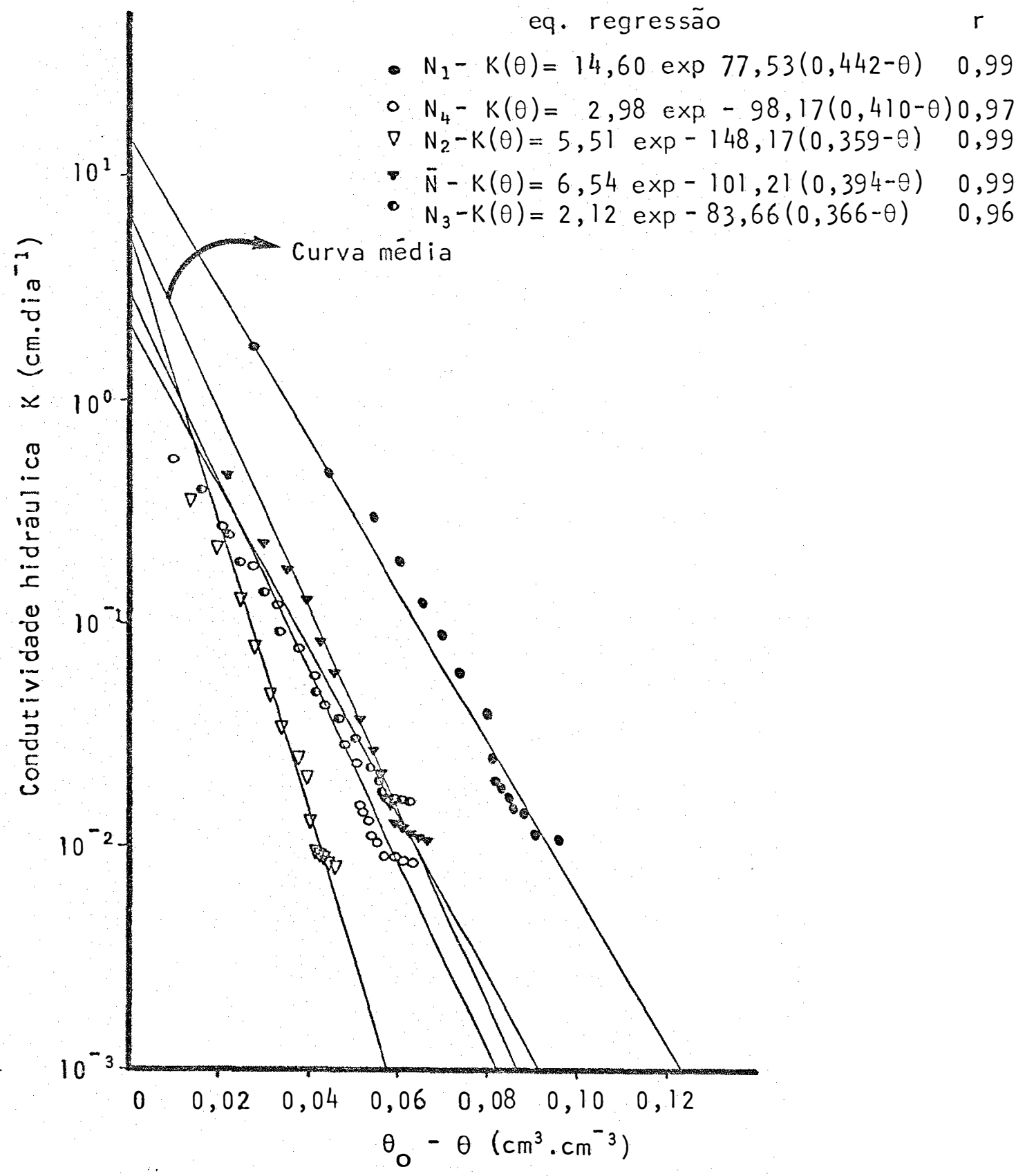

Figura 18 - Normalização das curvas da condutividade hidráulica em função da umidade de saturação. 


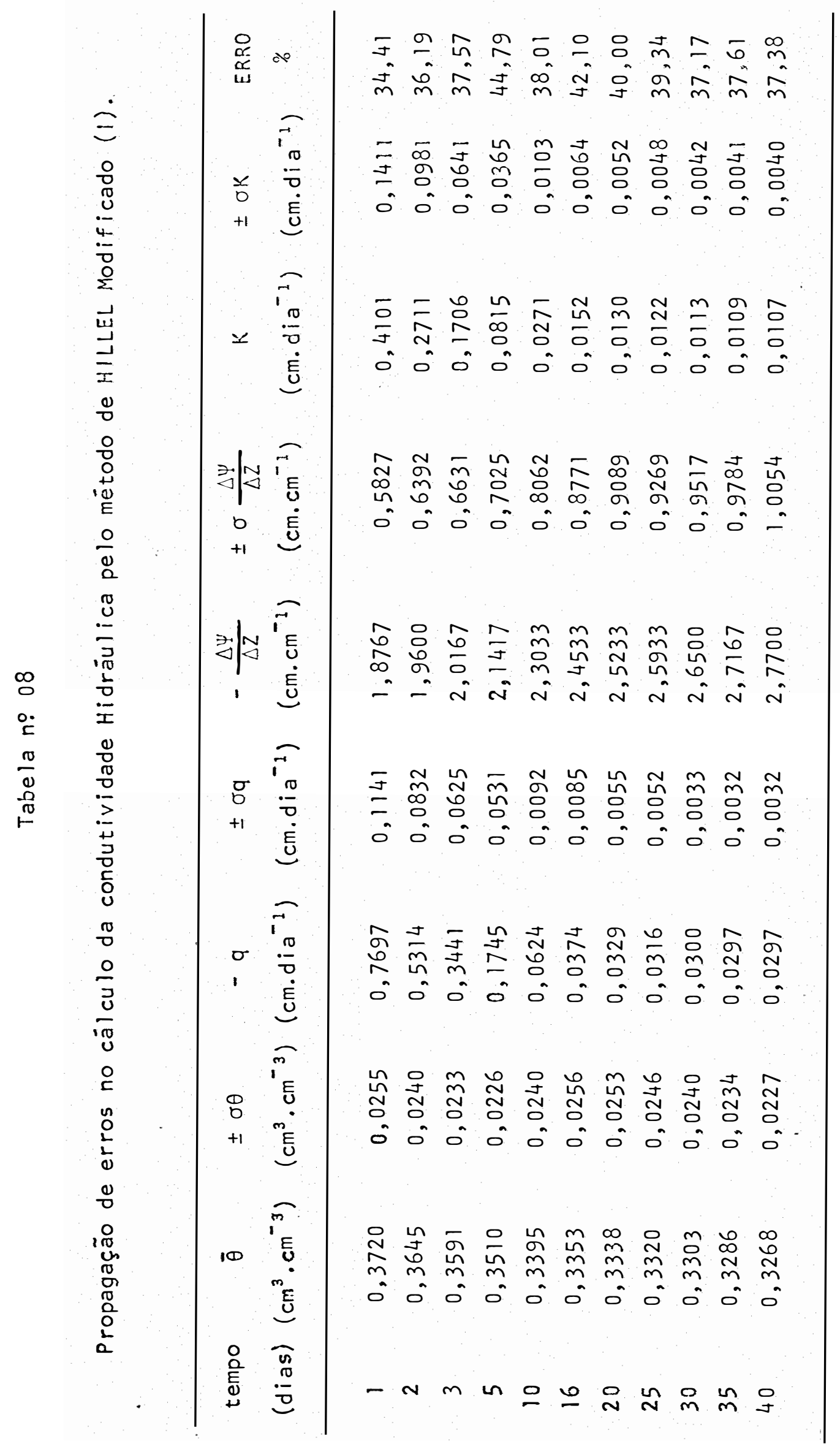


CHASE e RABINOWITZ (1967). Observa-se que esta técnica de análise de erro tende a tornar constante os erros envolvidos com as variáveis, independentemente do tempo, ressaltando-se algumas exceções, como para a densidade de fluxo que no quinto dia de redistribuição praticamente duplicou o erro, o que condiciona um valor praticamente constante do erro de $K(\theta)$ que foi aproximadamente de $39 \%$. Tais resultados são conflitantes com os obtidos por FLUHLER et alii (1977), pois segundo estes autores os erros envolvidos são menores próximo à saturação $(20$ a $30 \%)$ e maiores quanto o valor de $K(\theta)$ por pequeno (superior a $100 \%$ ). A justificativa que se propõe para explicar tal ocorrência são as técnicas de anālises de erro utilizadas por estes autores que foram diferentes da empregada no presente trabalho.

Com os dados da Tabela 8 construiu-se a Figura 19 que mostra a curva média de $K$ em função do conteúdo de água do solo, juntamente com o desvio padrão que se encontra representado pela ärea achureada . Procurando-se ilustrar a variação exponencial de $K$ em função da umidade $\theta$, tomou-se o ponto de umidade correspondente ao quinto dia de drenagem com o seu respectivo desvio padrão e plotou-se na Figura 19, obtendo-se assim, diretamente da curva os seguintes valores: $0,0107,0,0813$ e 0,4360 cm.dia ${ }^{-1}$ para $K(\bar{\theta})-\sigma, K(\bar{\theta}), K(\theta)+\sigma$ respectivamente, os quais correspondem à relação $1: 7,6: 40$. Do exposto constata-se a grande dificuldade da utilização da equação de Darcy para o cálculo da condutividade hidráulica em função do conteüdo de àgua do solo, pois, para um coeficiente de va riação de $6,4 \%$ da umidade $\theta$ pode-se cometer um erro mäximo na condutivida de hidräulica de 40 vezes. 


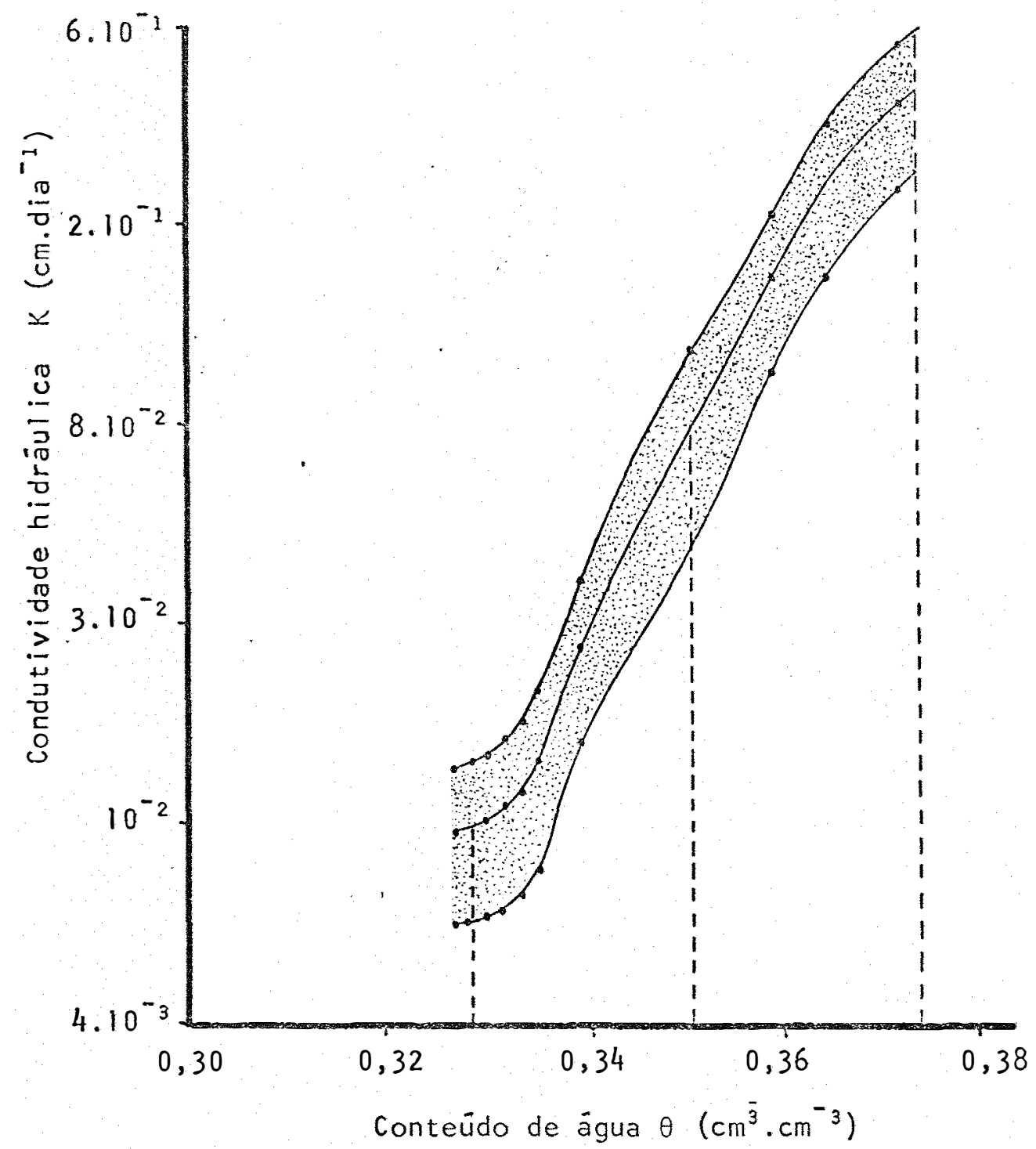

Figura 19 - Valores médios da condutividade hidrāulica em função do conteúdo médio de água do solo. A área achureada representa o desvio padrão dos valores médios obtidos dos quatro locais escolhidos ao acaso na parcela experimental. 


\section{CONCLUSÖES}

A condutividade hidrāulica em condições de saturação apre sentou um valor médio da ordem de $10 \mathrm{~cm}$ dia $^{-1}$ e durante oprocesso de drenagem interna para a profundidade de $120 \mathrm{~cm}$, o valor deste parámetro obit do através dos três métodos empregados, para o il dia de drenagem e com um teor médio de umidade de $0,372 \mathrm{~cm}^{3} \cdot \mathrm{cm}^{-3}$ foi de $4,25 \times 10^{-1} \mathrm{~cm} \mathrm{dia}^{-1}$ e para o 40 ? dia $\operatorname{com} \theta=0,327 \mathrm{~cm}^{3} \cdot \mathrm{cm}^{-3}$ foi de $9,34 \times 10^{-3} \mathrm{~cm} \mathrm{dia}{ }^{-1}$.

0 processo de drenagem interna no perfil deste Alfisol d $\bar{i}$ fere sensivelmente entre camadas, pois o movimento de água torna-se negli gível na $1 ., 2 ., 3$. e $4^{a}$. camada no período de $6,8,16$ e 16 dias com os seguintes teores de umidade: 0,$348 ; 0,319 ; 0,296$ e $0,335 \mathrm{~cm}^{3} . \mathrm{cm}^{3}$ respectivamente. Isto vem mostrar que o conceito de capacidade de campo nao é estático e sua determinação obrigatoriamente deverá ser feita a campo.

Os métodos empregados para a determinação da condutividade hidráulica apresentaram-se bem coerentes, pois os resultados obtidos pelos três métodos não diferiram em ordem de grandeza. Entretanto, sugere-se a utilização do método de HILLEL Modificado (11) por ser menos la- 
borioso e ainda apresentar as vantagens de uma maior precisão no cálculo da densidade de fluxo e manter a linearidade da curva $K(\theta)$ quando a variação da umidade $\theta$ for relativamente mui to pequena.

Os valores da condutividade hidráulica obtidos em quatro lo. cais escolhidos ao acaso na parcela, mostraram uma grande variabilidade espaçial, pois constatou-se uma variação de aproximadamente 100 vezes deste parâmetro entre dois locais, para um mesmo conteúdo de água. Considerando que a umidade $\theta$ tạbém apresenta variabilidade espacial, constata-se então a veracidade do valor de $K(\theta)$ somente quando este parâmetro for obtido no mesmo local onde se mediu a umidade $\theta$.

A técnica empregada para determinação da propagação de erros das variáveis envolvidas no cālculo da condutividade hidráulica,apresentou uma tendencia de tornar constante os erros das variáveis, independentemente do tempo. Tal fato implicou num erro praticamente constante de $\bar{k}(\theta)$ que foi aproximadamente de $39 \%$. 
6. RESUMO

0 estudo da condutividade hidräulica de um Alfisol foi rea lizado numa parcela experimental de $10 \mathrm{~m} \times 10 \mathrm{~m}$, instalada nas proximidades do posto meteorológico do Departamento de Física e Meteorologia da Escola Superior de Agricultura "Luiz de Queiroz". Utilizou-se o método do perfil instantâneo, empregando: a) o procedimento sugerido por HILLEL et alii (1972), b) a modificação introduzida por CHO et alii (1977), denominada Método de HILLEL Modificado (1) e c) a modificação na determinação do fluxo através de um processo analítico, chamada de Método de HILLEL Modificado (11). Posteriormente, procedeu-se a um estudo de variabilidade espacial da condutividade hidráulica dentro da parcela experimental e calculou-se também a propagação de erros na determinação do valor médio deste parâmetro.

Para elaboração deste trabalho instalaram-se na parcela experimental vinte tensiômetros, sendo dez colocados à profundidade de $105 \mathrm{~cm}$ e dez à $135 \mathrm{~cm}$ e quatro tubos de acesso de alumínio para receber a sonda de neutrons atē a profundidade de $140 \mathrm{~cm}$. Tal instrumentàl tinha como finalidade possibilitar a obtenção de dados de umidade e de po- 
tencial da água do solo. A parcela foi saturada e coberta com plástico para evitar fluxo de água na.superfície e a partir deste momento leituras nos tensiômetros e com a sonda de neutrons foram realizadas durante 38 dias, que foi o período de duração do experimento.

0s resultados obtidos através dos três procedimentos empre gados para o cálculo da condutividade hidráulica são bem compativeis,permitindo admitir-se a validade destes métodos. O método de HILLEL Modificado (II) devido sua linearidade mesmo para pequena variação de umidade, apresenta-se como o mais sugestivo. Para um mesmo conteúdo de àgua do solo obteve-se uma variação na condutividade hidrāulica no sentido horizontal dentro dạ parcela de aproximadamente 100 vezes. A utilização da curva média de $K(\theta)$ está sujeita a um erro de $39 \%$ como se verificou pelo estudo de propagação de erros. 


\section{SUMMARY}

Hydraulic conductivity of an Alfisol was studied under field conditions, on a $10 \times 10 \mathrm{~m}$ experimental plot. The method of the instantaneous profile was used in the following maner: a) according to HILLEL et alii. (1972); b) using the modification introduced by $\mathrm{CHO}$ et alii (1977) which was called HILLEL'S Modified Method (1), and c) calculating soil water fluxes through analytical proceedure, which was called HILLEL'S Modified Method (11). Later a study of spatial variability of hydraulic conductivity data was made, including also the error propagation in the estimation of average values.

Soil water potential measurements have been made through tensiometer readings, ten located at $105 \mathrm{~cm}$ depth and 10 located at $135 \mathrm{~cm}$ depth and soil water content thorough four neutron access tubes of $140 \mathrm{~cm}$ depth. The soil profile was saturated by ponding water on the surface until steady infiltration and later covered with plastic to prevent surface evaporation. The drainage process was observed through a period of 38 days. 
The results obtained through the three methods of calculation are compatible,. showing the validity of all, although HILLEL'S Modified Method (II) has prooved to be the best. For the same soil water content the hydraulic conductivity varied horizontaly within the plot of a factor of approximately 100. The use of an average $k(\theta)$ relation is subject to an error of $39 \%$. 
8. LITERATURA CITADA

BAKER, F.G., P.L.M. VENEMAN e J. BOUMA, 1974. Limitations of the Instantaneous Profile Method for Field Measurement of Unsaturated Hidraulic Conductivity. Soil Sci. Soc. Amer. Proc., 38:885-888.

BUCKINGHAM, E. 1907. Studies on the Movement of Soil Moisture. Bul. Bur. Soils U.S. Dept: Agr., 38 .

BRUCE, R.R., 1972. Hidraulic Conductivity Evaluation of the Soil Profile from Soil Water Retention Relations. Soil Sci. Soc. Am. Proc., 36: $555-561$.

CHAZE, G.D. e J.L. RABINOWITZ, 1967. Principles of Radioisotope.

Methodology. Third Edition. Minneapolis, Burgess Publishing Company. 633p. 
CHO, T., Y. NOMURA, T. YANO, T. YAMAMOTO e M. INOUE. 1975. Application. of Neutron Moisture Meter for Estimation of Evapotranspiration - Water Management in a Saud Dune Area. Report for Co-ordinated Research Programme on the Use of Radiation and I sotope Techniques in Studies of Soil-Water Regime, IAEA. Tottori University. 18p.

CHO, T., Y. NOMURA, T. YANO, S. SHIKASHO E M. INOUE. 1977. The Use Surface-Type and a Depth-Type Neutron Moisture Meter in Studies of Soil Water Regimes - Water Management in a Saud Dune Area. A Report for the Coordinated Research Programe on the Use of Radiation and Isotope Techniques in Studies of Soil-Water Regimes. IAEA Tottori University. $85 p$.

ClIFFOED, A.A. 1973. Multivariate Error Analysis. Appl. Sci. Publ., London. $112 p$.

DARCY, H. 1856. Les Fontaines Publiques de la Ville de Dijon. Paris, Victor Dalmont. $592 p$.

DAVIDSON, J.M., L.R. STONE, D.R. NIELSEN e M.E. La RUE. 1969. Field Measurement and Use of Soil Properties: Water Resour., 5:1312.

FERRAZ, E.S.B. 1972. Estudo da Evapotranspiração Real Atravēs da Medida. no Solo por Moderação de Neutrons. Piracicaba, S.P. 40p. BC-005, CENA. 
FLÜHLER, H., M.S. ANDAKANI e L.H. STOLZY. 1976. Error Propagation in Determining Hidraulic Conductivities from Successive Water Content and Pressure Head Profiles. Soil Sci. Amer. Journ., 40:830-836.

HAAN, G.J. e S.S. SHAPIRO. 1967. Statistical Models in Engineering. N.Y., Jonh Wiley E Sons. 335p.

HILLEL, D. 1970. Agua e Solo. Fenômenos e Princípios Físicos. Porto Ale gre. Ed. Meridional "EMMA". 231 p.

HILLEL, D., V.D. KRENTOS E Y. STYLIANOU. 1972. Procedure and Test of an Internal Drainage Method for Measuring Soil Hidraulic Conductivity in situ. Soil Sci. Amer. Proc., 114:395-400.

HILLEL, D., C.H.M. Van BAVEL. 1976. Simulation of Profile Water Storage as Related to Soil Hidraulic Properties. Soil Sci. Amer. Journ., 40: $807-815$

HUBBERT, M.K. 1956. Darcy's baw and Field Equations of the flow of Underground Fluids. Amer. Inst. Mining Met. Petrol Eng. Trans., 207: $222-239$

KLUTE, A. 1965. Laboratory Measurement of Hidraulic Conductivity of Satured Soil: In: Black, C.A. Methods of Soil Analysis. Amer. Soc. Agron. 253-261. . 
LALIBERTI, G.E., A.T. COREY E R.H. BROOKS. 1966. Properties of Unsatured porous Media. Hydrology Paper. Colorado State Univ. 17.

La RUE, M.E., D.R. NIELSEN e R.M. HAGAN. 1968. Soil Water Flux Below a Ryegrass Root Zone. Aaron. Journ., 60:625-629.

MARINI, P., P. VILLEMIN e O. JOURDAN. 1977. Definition des Proprietes. Hydrodinamiques des Sols du Perimetre Sucrier D'Avalaiva. Contrat de Recherche avec L'Agence Internationale de L'Energie Atomique. Université de Madagascar. $41 p$.

MARSHAL, T.J. 1958. A Relation between Permeability and size Distribution of pores'. Journ. Soil Sci., $9: 1-8$.

MILINGTON, R.J. e J.P. QUIRK. 1959. Permeability of Porous Media. Nature, 183:387-389.

MILLER, R.J. e P.F. LOW. 1963. Threshold Gradiente for Water Flow in Clay Sistems. Soil Sci. Soc. Amer. Proc., 27:605-609.

NIELSEN, D.R., D. IRKHAN e R.W. Van MIJK. 1961. Difusion equation calculations of Field Soil Water Infiltration Profiles. Soil Sci. Soc. Amer. Proc., 25:165-168.

NIELSEN, D.R., J.W. BIGGAR e K.T. ERH. 1973. Spatial Variability of Field-Measured Soil-Water Properties. Hilgardia, 42:215-259. 
RANZANI, G., 0. FREIRE e T. KINJO. 1956. Carta de Solos do Município de Piracicaba. Piracicaba, SP., C.E.S., Mimeografado. 83 P.

REICHARDT, K. E P.L. LIBARDI, 1974. An Analysis of Soil-Water Movement. in the Field: 1. Hidrological Field Site Characterization. Piracicaba, SP. 21P. BC-021, CENA.

REICHARDT, K., P.L. LIBARDI e D.R. NIELSEN. 1975. Unsatured Hidraulic Conductivity Determination by a Scaling Technique. Soil Sci. Soc. Amer., 120:165-168.

REICHARDT, K. 1975. Processos de Transferência no Sistema Solo-PlaritaAtmosfera. 3a. Ed. São Paulo, CENA/USP/CNEN e Fundação Cargil1. $286 p$.

REICHARDT, K., F. GROMANN, P.L. LIBARDI e S.V. QUEIROZ. 1975: Spatia? Variability of Physical Properties of a Tropical Soil: II Soil Water. Retention Curves and Hidraulic Conductivity. Piracicaba, SP. $24 \mathrm{p}$. BT-005, CENA.

RICHARDS, L.A. 1931. Capillary Conduction of Liquid through Porous Media. Physics, 1:318-333.

RICHARDS, S.J. e L.V. WEEKS. 1953. Capillary Conductivity Values from Moisture, Yield and Tension Measurements on Soil Columns. Soil Sci. Soc. Amer. Proc., 17:206-209. 
RICHARDS, L.A., W.R. GARDNER e G. OGATA. 1956. Phisical Processes, Determining Water loss from Soil, Soil Sci. Soc. Amer. Proc., 20: $310-314$

RICHARDS, S.J. 1965. Soil Succion Measurement with Tensiometers. In: Black, C.A. Methods of Soll Analysis. Amer. Soc. Agron. 153-158.

ROSE, C.W., W.R. STERN E J.E. DRUMOND. 1965. Determination of Hidraulic Conductivity as a function of Depth and Water content for Soil in situ. Aust. Journ. Res., 3:1-9.

ROULIER, M.H.; L.H. STOLZY, J. LETEY e L.V. WEEKS. 1972. Aproximation of Field Hidraulic Conductivity by Laboratory Procedures on Intact Cores. Soil Sci. Amer. Proc., 36:387-393.

SWARTZENDRUBER, D. 1962. Non Darcy Behavior in Liquid Satured Porous Media. Journ. Geophisies Res., 67:5205-5213.

Van BAVEL, C.H.M., G.G. STIRK E K.J. BRUST. 1968. Hidraulic Properties of a Clay Loam Soil and the Field Measurement of Water Uptake by Roots.. I- Interpretation of Water Content and Pressure.Profiles. Soil Sci. Soc.Amer. Proc:, 32:310-317.

VERPLANCKE, H., R. HARTMANN E M.De BOODT. 1977. An Analysis of Soil. Water Movement in the Field. Report for Co-ordinated Research Programme on the Use of Radiation and I sotope Techniques in Studies of Soil-Water Regime, IAEA State University of Ghent, Belgium. 19p. 
YOUNG, E.G. 1964. Infiltration Method of Measuring the Hidraulic Conductivity of Unsatured Porous Materials. Soil Sci. Soc. Amer. Proc., 97:307-313. 